\title{
Opening the black box of academic entrepreneurship: a bibliometric analysis
}

\author{
Igors Skute ${ }^{1}$ (D)
}

Received: 1 November 2018 / Published online: 4 May 2019

(c) The Author(s) 2019

\begin{abstract}
The increasing importance of academic entrepreneurship as a key mechanism for new innovative advancements and regional economic developments fostered a development of this research domain. The burgeoning literature examining key antecedents and consequences of academic entrepreneurship resulted in complex, multifaceted concept development, which hinder both the possibilities to grasp the crucial interlinkages and a comprehensive assessment of the latest theoretical contributions. Thus, to decrease the current risk of the field's further fragmentation and to support the comparison with the new emerging patterns, this paper seeks to develop new bibliometric insights and outline a nuanced research agenda for further advancements. To conduct a quantitative literature review, this paper employs bibliographic coupling on a sample of 615 Web of Science peer-reviewed articles on academic entrepreneurship. To conduct a comprehensive interpretation of the bibliometric findings, I perform additional hierarchical clustering of the frequent terms and content analysis of the publications. The results indicate that the academic entrepreneurship research field is based on four interconnected clusters: (1) the anatomy of an entrepreneurial university and its main components, (2) university spinoffs and technology commercialization, (3) the identities of academic entrepreneurs and their motivations and barriers in entrepreneurial activities, and (4) knowledge transfer and regional economic impacts. These findings are of high importance to academics who seek to enhance entrepreneurial processes and to policymakers interested in stimulating academic entrepreneurship.
\end{abstract}

Keywords Academic entrepreneurship · Bibliometrics · Bibliographic coupling · Knowledge transfer

JEL Classification L26 $\cdot \mathrm{M} 13 \cdot \mathrm{O} 31 \cdot \mathrm{O} 32$

Igors Skute

i.skute@utwente.nl

1 NIKOS-ESIM (Department for Entrepreneurship, Strategy and Innovation Management), University of Twente, PO Box 217, 7500 AE Enschede, The Netherlands 


\section{Introduction}

Acknowledging the strong interest in academic entrepreneurship in the past years, university spinoffs (USOs) and entrepreneurial academics are increasingly considered as great potential sources of new and often disruptive innovations. Grounded in scientific discoveries, they contribute to the innovative capacity and economic development of regions and countries (Bienkowska et al. 2016; Galan-Muros et al. 2017; Marzocchi et al. 2017; Perkmann et al. 2013). Thus, understanding the process and potential impacts of academic entrepreneurship, broadly understood as commercialization of scientific research results, becomes crucial for academics, practitioners, and policymakers (Balven et al. 2018; Fini et al. 2018; Sandström et al. 2018).

The importance of academic entrepreneurship has been widely recognized in the literature, evidenced by the notable increase of relevant publications in the past years (Bock et al. 2017; Bozeman et al. 2013; Czarnitzki et al. 2014; Gümüsay and Bohné 2018; Skute et al. 2017; Zavale and Langa 2018). Prior research signals the potential to better understand this phenomenon at the individual, organizational, and institutional levels (Hayter et al. 2018; Rothaermel et al. 2007). Based on the recent developments and governmental initiatives, academic institutions are challenged to balance more traditional activities of education and research with increasing commercialization efforts (Galan-Muros et al. 2017; Grimaldi et al. 2011). This has facilitated the development of various research threads in the academic entrepreneurship literature, which has focused on antecedents and consequences of entrepreneurial universities, the process and key determinants of USO development, and the entrepreneurial competencies of researchers engaging in research commercialization activities (Hayter et al. 2018; Mathisen and Rasmussen 2019; Perkmann et al. 2013; Rasmussen and Wright 2015; Vohora et al. 2004).

Thus, to decrease the risk of the field's fragmentation and to support the systematic generation of relevant and interesting knowledge on academic entrepreneurship, it is necessary to understand both the structure of the current body of literature, and the extent to which it has already tackled recently suggested research opportunities (Grimaldi et al. 2011; Hayter et al. 2018; Mathisen and Rasmussen 2019; Siegel and Wright 2015; Wright 2014). To examine the current state-of-the-art literature on academic entrepreneurship and to compare the new emerging research foci, I seek to generate an evidence-based roadmap for spurring focused academic entrepreneurship research so as to move the field forward.

Here, the main departure points are the recent narrative reviews of the academic entrepreneurship literature, i.e. the work of Grimaldi et al. (2011), Perkmann et al. (2013) and Miranda et al. (2018), who have suggested research agendas. Further, Siegel and Wright (2015) recently proposed paradigmatic shifts concerning academic entrepreneurship practices, acting as guidance for future research. Specifically, they stress the emerging relevance of considering the rationale of academic entrepreneurship (why, moving towards social entrepreneurship), new forms of academic entrepreneurship (what), new actors entering academic entrepreneurship (who, students and graduates), and new modes to facilitate academic entrepreneurship (how).

To address these challenges, I conducted a quantitative bibliometric analysis of 615 peer-reviewed articles, employing bibliographic coupling. This analysis type, which has been acknowledged in the past years, enables one to perform a comprehensive assessment of the state-of-the-art literature in a particular research field (Kovács et al. 2015; Meyer et al. 2014; Teixeira and Mota 2012). Further, I build on the results of bibliographic coupling, introducing both quantitative and qualitative efforts to extend the research 
findings, specifically by employing hierarchical clustering and content analysis of selected publications.

The bibliographic coupling's results indicate that the academic entrepreneurship research field is based on four interconnected clusters: (1) the anatomy of an entrepreneurial university and its main components, (2) university spinoffs and technology commercialization, (3) the identities of academic entrepreneurs and their motivations and barriers in entrepreneurial activities, and (4) knowledge transfer and regional economic impacts.

This paper makes the following contributions: First, by employing both quantitative and qualitative methods, I contribute systematic insights to the evolution of the academic entrepreneurship field. I consolidate the main research streams of the past 10 years, providing a comprehensive overview of the field. Second, I identify the multifaceted and interconnected nature of the academic entrepreneurship research field, outlining new emerging trends, encouraging further research advancements of previously under-researched determinants and their interplays in the identified thematic areas at the individual, organizational, and institutional levels.

The remainder of this article is structured as follows. In "Research design" section, I elaborate research design and methods. I then present a statistical overview and the results of bibliographic coupling, discuss the main findings, and identify the main implications for academics and policymakers. I also outline the emerging patterns in the research field and future research avenues. Finally, I describe the study's limitations and suggestions for further advancements.

\section{Research design}

To construct the dataset for this bibliometric literature review, I retrieved articles from the Thomson Reuters Web of Science database. The Web of Science Core Collection database is recognized as covering a notable range of high-ranking journals and peer-reviewed articles of high quality. While I note the availability of other databases, I follow the methodological approach of previous research (e.g., see Meyer et al. 2014); since this study is designed to primarily examine the patterns of indicators, I accept this limitation. To construct the dataset, I designed the following search query: "academic entrepreneurship" OR "academi* spin*" OR "universit*spin*" OR "academi* commerciali*ation" OR "universit* commerciali*ation" OR "entrepren* universit*" OR "entrepren* academi*". I restricted the search query to searching in titles, abstracts, and/or keywords while accepting term spelling variations (e.g., academic spinoffs, academic spinoffs, academic spinouts, etc., but controlled for non-related terms such as spine). Next, I restricted the search to 2008 to 2017 so as to capture the key publications and topics in the past 10 years, which also allowed me to identify the recent emerging developments in this research field. This search query covered a relatively broad publications scope; to reduce the risk of including false positive items with no complementary value to the constructed dataset, I conducted further inspections. While the initial search resulted in 978 publications, I selected only 'article' publications, which reduced the sample to 650 publications. Further, I examined publications from less matching Web of Science categories. I further refined the results and excluded a list of categories with no value for the academic entrepreneurship literature (I excluded 26 categories, such as radiology, medical imagining, thermodynamics). This led to the final sample of 615 articles, referring to 7259 citations and 21,429 references. To avoid false positive items in the dataset, I inspected all articles that formed a 
corpus for bibliographic coupling for the inclusion of the abovementioned keywords in the titles and/or abstracts and/or keywords.

To examine publication scientific mapping patterns and to assess the relatedness of themes in the academic entrepreneurship literature, I used bibliographic coupling technique (Boyack and Klavans 2010; Kessler 1963). Bibliographic coupling focuses on matching articles in a dataset based on shared references. This technique is increasingly used in various research fields, including the management and entrepreneurship literatures. Bibliographic coupling is generally applicable for interpretation of the current state of a research field and the emerging patterns owing to its ability to match or 'couple' articles, based on their shared references, which are older than the focal publications (Boyack and Klavans 2010; Kovács et al. 2015).

I constructed and visualized thematic clusters based on normalized relatedness measures. I deemed an association strength measure appropriate for normalizing co-occurrence data, in accordance with the methodological approach of previous studies (Van Eck and Waltman 2009, 2010). Detailed methodological overviews, including calculations of the association strength measure and comparisons to other well-known measures, are provided in Van Eck and Waltman (2009) and Waltman et al. (2010). I constructed clustered bibliometric networks by adopting the visualization of similarities (VOS) approach, using an optimized algorithm of VOSviewer 1.6.5 (Van Eck and Waltman 2007, 2010).

Further, to interpret and label the resulting clusters of bibliographic coupling, I used text mining and hierarchical clustering of subtopics. To analyze the content of selected article abstracts, I conducted text pre-processing using the 'tm' package in R (Feinerer and Hornik 2012). I removed all punctuation marks, numbers, and extra white spaces from the selected abstracts, and converted all uppercase letters to lowercase ones. Also, I removed stopwords and stemmed all remaining terms. I included the $\mathrm{N}$-grams in the dataset up to an order of $n=3$, using the 'RWeka' package (Hornik et al. 2007). Thus, I created the dataset based on unigrams only, unigrams and bigrams, bigrams and trigrams, etc. In the next step, I transformed all unique words and word combinations into a 'bag of words' representation via a document term matrix. I based further word frequency analysis and visualizations on the created document term matrix. To obtain the results of hierarchical clustering, I used the 'hclust' function of the 'Stats' package, using the Euclidean distances and Ward.D method (Team and Worldwide 2002).

Finally, I did qualitative content analysis of the clustered publications, on the basis of the bibliographic coupling and text mining results. I analyzed the content of titles, abstracts, and keywords of the clustered publications. I then qualitatively analyzed the 20 most relevant articles (based on total and normalized citations) with the highest number of links in each cluster so as to detect the current and emerging patterns in the literature, using Atlas.ti software. I calculated the normalized citations of a publication as follows: the number of citations of the publication divided by the average number of citations of all documents published in the same year. The normalization corrected for the fact that older publications have had more time to receive citations than more recent publications. To extend the results with additional insights, I enriched the discussion of the results and emerging research patterns with additional literature.

\section{Results}

The number of articles published on the topic of academic entrepreneurship and USOs has significantly increased in the past 3 years, compared to this research field's overall positive development in the past decade (see Fig. 1). This confirms the growing interest in 
academic entrepreneurship and associated determinants in the scholarly literature (Hayter et al. 2018; Miranda et al. 2018; Perkmann et al. 2013; Teixeira and Mota 2012; Zavale and Langa 2018).

The results in Fig. 2 show that the three leading peer-reviewed journals publishing the most articles on academic entrepreneurship were the Journal of Technology Transfer (83 publications), followed by Research Policy and Technovation (45 and 27 publications, respectively). While these three leading journals accounted for $25.2 \%$ of total publications, the remaining journals list is relatively well-distributed. This indicates that, besides the three top journals publishing the most insights in this research domain, academic entrepreneurship is a broad topic that includes a wide variety of elements that are addressed from different perspectives. This finding is in line with the distribution of Web of Science categories illustrated in Fig. 3. Unsurprisingly, the three most popular Web of Science categories relate to the academic entrepreneurship literature cover management (341 publications), business (152 publications), and industrial engineering (122 publications) categories. For a better understanding, notably, a publication can be assigned to more than one category. These three most common categories are associated with $56.9 \%$ of publications in the dataset, suggesting that academic entrepreneurship is a specific niche topic in management and entrepreneurship literature; nonetheless, the results signal that academic entrepreneurship is also a multidisciplinary phenomenon that is receiving attention from diverse research fields, such as biomedical technologies, health policy services, women's studies and other research fields in which the entrepreneurial academic organizations and their actors are key subjects of studies.

Figure 4 illustrates the author distribution by number of publications authored or coauthored in the constructed dataset. The dataset included 636 authors. The leading author with most 24 (co)authored articles (accounting for 3.9\% of all publications) is Mike Wright, followed by Maribel Guerrero (13 (co)authored publications). Then, the top five authors list contains three authors with 12 publications each: David Urbano, Einar Rasmussen, and Mirjam Knockaert. With five leading authors accounting for less than $12 \%$ of

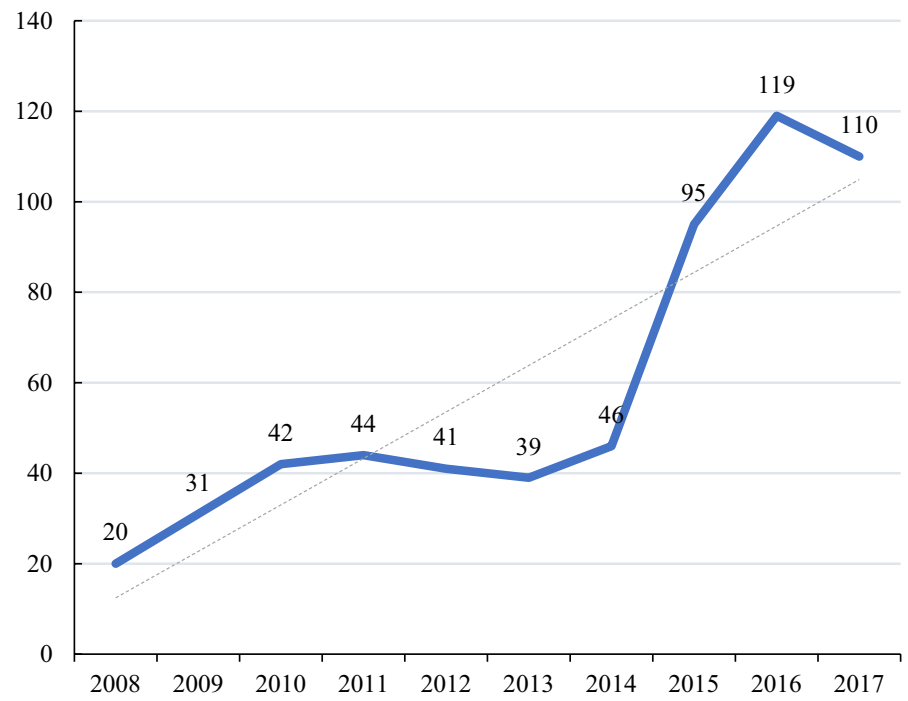

Fig. 1 Distribution of WOS publications on academic entrepreneurship between 2008 and $2017(\mathrm{n}=587)$ 


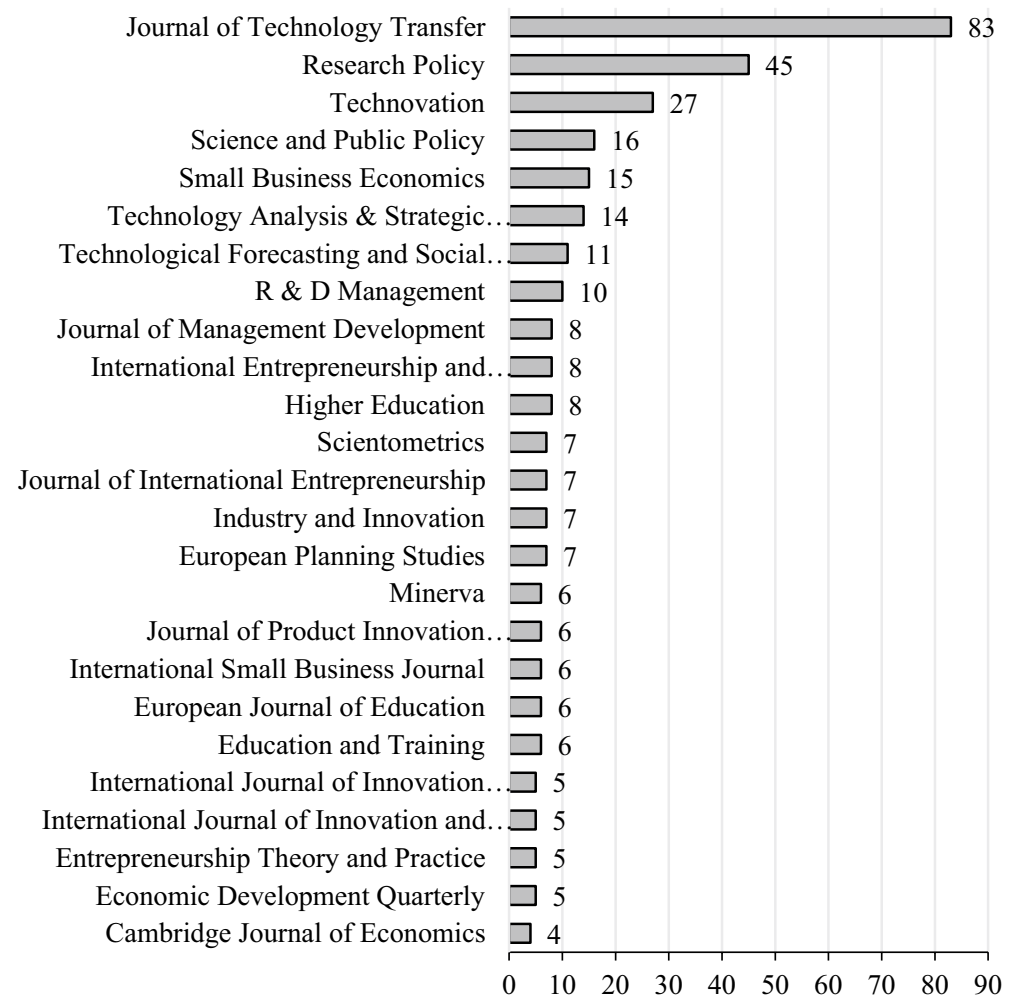

Fig. 2 Distribution of the scientific journals publishing the most articles in the academic entrepreneurship domain (top 25 journals)

the total number of selected authors, the results indicated a notable variety. However, most of the authors are from related research domains, which supports the academic entrepreneurship domain's distinctness.

Figures 5 and 6 illustrate the authors' geographical distribution and their affiliated organizations and countries. The results show that the highest number of publications were (co)authored by researchers from Ghent University, Imperial College London, and Autonomous University of Barcelona (with 29, 28, and 18 associated publications, respectively). Figure 6 indicates that most publications were (co)authored by researchers affiliated with the U.S. (123 associated publications). While England remained second with 106 author affiliations, Italy had the third highest number (71). More detailed examinations indicated that studies of academic entrepreneurship and associated determinants are dominated by the U.S. and Europe, signaling that crucial findings should be generalized within this institutional environments scope, especially concerning the issues of the most recent policy developments and governmental initiatives, facilitating the further development of academic entrepreneurship (Fini et al. 2017; Hayter et al. 2018).

The bibliographic coupling's results are illustrated in Fig. 7. The visualized bibliometric network includes four interconnected clusters with unique labels based on the shared references and their patterns. To identify all themes and emerging topics in this research field, I applied no restrictions concerning the number of citations necessary to be included in 


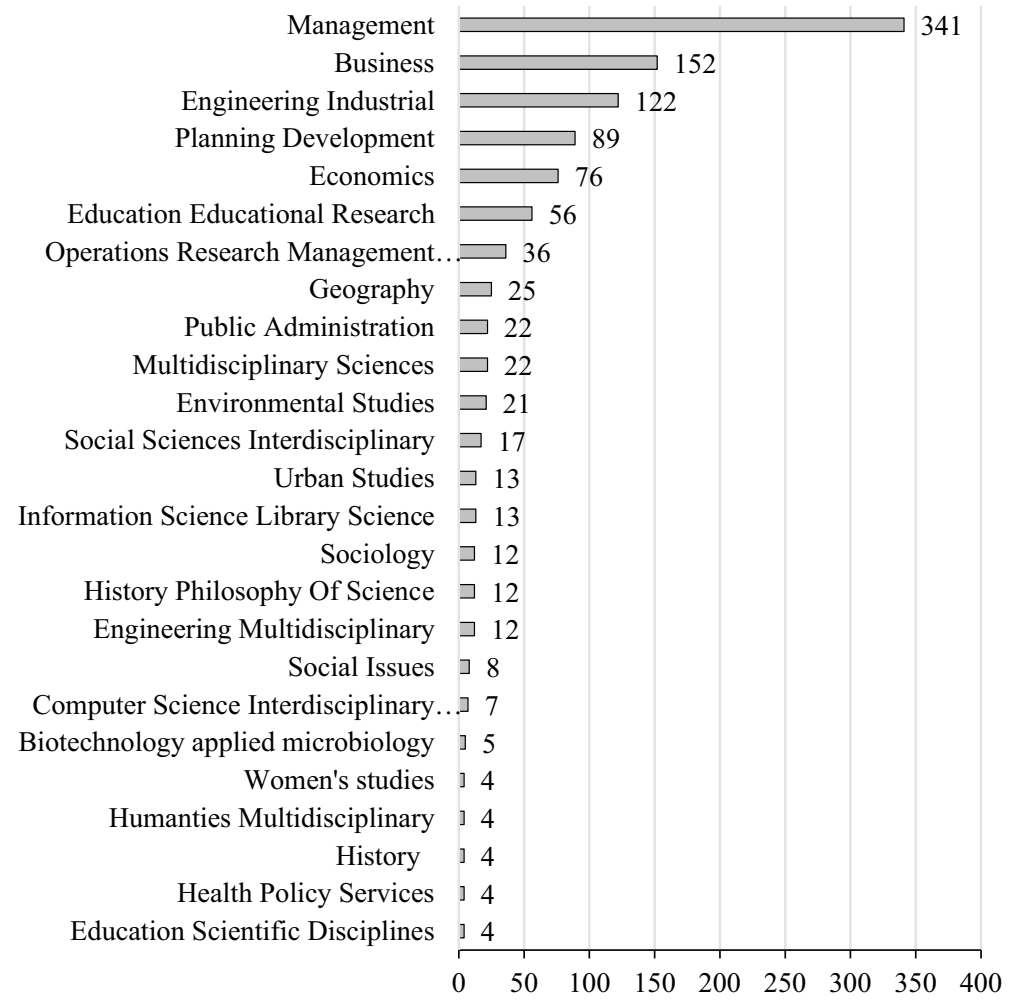

Fig. 3 Distribution of WOS categories corresponding to the publications in the academic entrepreneurship domain (top 25 categories)

bibliographic coupling analysis. Thus, from a total sample of 615 articles included in the analysis, I clustered 601. The excluded articles represent a sample of publications with no shared references with other articles in the dataset and therefore could not be connected. Further, five clusters included 4, 4, 3, 3, and 1 publications each; owing to low applicability and little value for further interpretation, I excluded these from the results and further analysis. Thus, the final sample of analysis contained 587 articles.

Each item depicted in the visualized bibliometric network represents a unique publication from the dataset that is clustered based on the likelihood of having a shared reference. Items assigned to the same cluster share a higher probability, while colors show all distinct clusters and articles belonging to them. Further, each item has a specific weight, based on the number of total citations, total links, and total link strength of the publications. For a more illustrative overview, publications with higher number of total citations are displayed in a larger size (Van Eck and Waltman 2010; Waltman, Van Eck, and Noyons 2010).

Based on the bibliographic coupling's results, I retrieved the abstracts of publications and additional information about the publications for further analysis, specifically text mining and hierarchical clustering, and full content of publications for content analysis of four identified clusters. I based the following analysis and description of the bibliographic coupling's results on the analysis of term frequencies and hierarchical clustering, as well as full content analysis of the key publications in each cluster. 


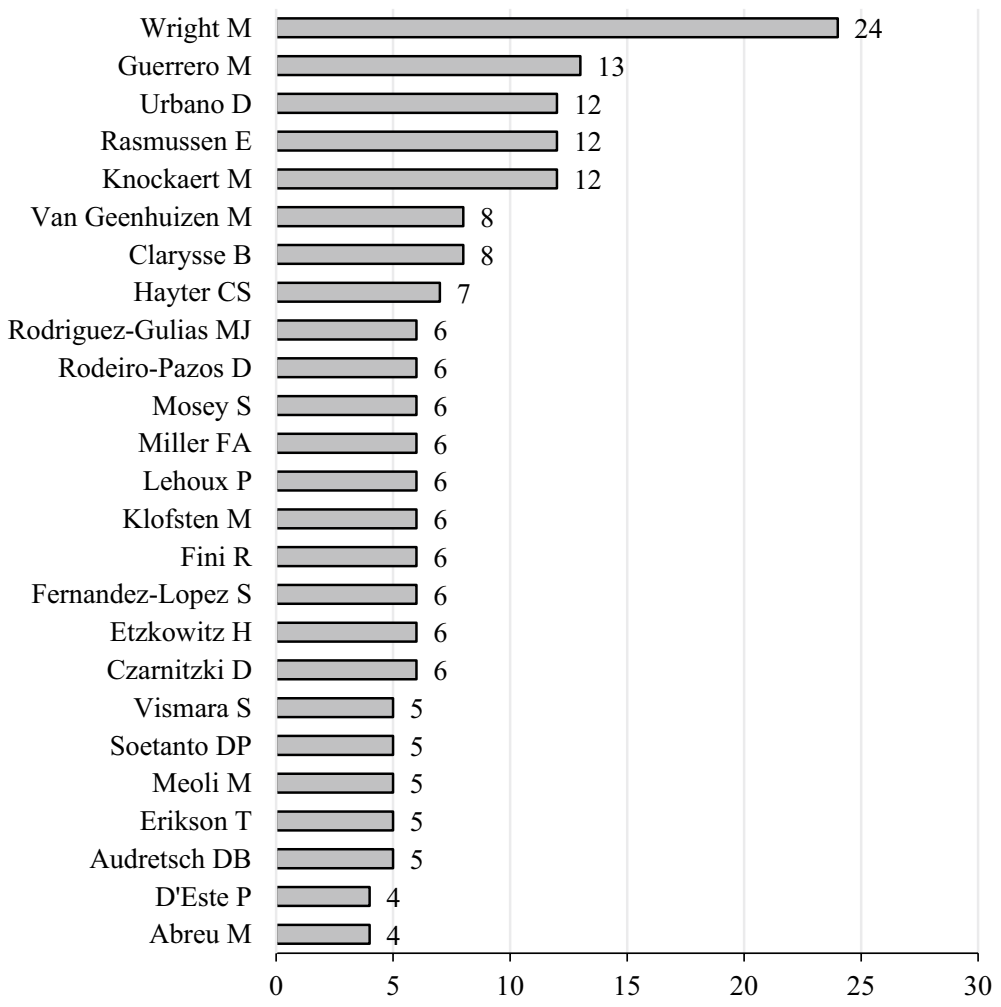

Fig. 4 Distribution of authors by the number of publications authored or co-authored (top 25 authors)

\section{Cluster 1: the anatomy of entrepreneurial university}

Figures 8 and 9 illustrate a distribution of the pre-processed key term frequencies of Cluster 1 publications, based on the bibliographic coupling's results. Specifically, Fig. 8 shows the most frequent words in Cluster 1 publications' abstracts, including $\mathrm{N}$-grams up to an order of $n=3$. Figure 9 illustrates the hierarchical clustering's results of the terms in Cluster 1. Cluster 1's dendrogram depicts closeness or dissimilarity of the terms, based on the Euclidean distances (Height axis), and Ward.D method. This implies that terms with the lowest dissimilarity, based on the Euclidean distance or height in the illustrated dendrogram, are connected in a cluster. To make further connections and estimate the dissimilarity of merged terms with others, I used recomputed distance values based on the Ward.D method. I repeated the procedure until all terms were clustered. Since it was impractical to clearly visualize all terms in Cluster 1's publications, I set the term matrix sparsity threshold to 0.75 .

In more practical terms, the depicted dendrogram is a compact visualization of a dissimilarity matrix. Two main clusters are identified and highlighted by red lines, based on the highest distinct distance. Although it is possible to identify more clusters, the purpose of hierarchical clustering here is to display each cluster's content and their interconnections in order to label the bibliographic coupling's results. Thus, the 


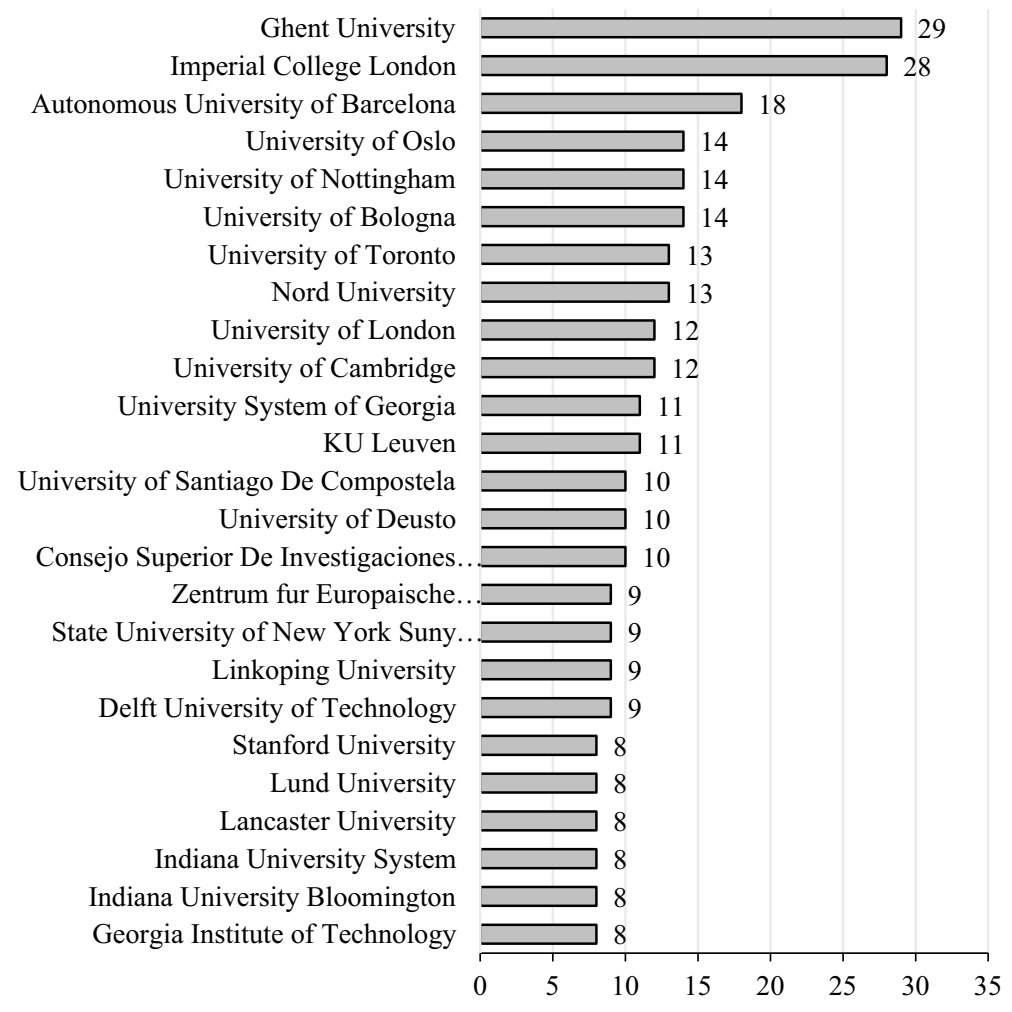

Fig. 5 Distribution of author affiliations to organizations based in selected publications (top 25 organizations)

argumentation focuses on analyzing the clusters and their components rather than on identifying a larger variety of subclusters.

Thus, analyzed publications in this cluster are related to the antecedents and consequences of entrepreneurial universities and their associated determinants. Specifically, a central thread of publications in this cluster focuses on explaining the roles of the university as a catalyst for regional economic and societal development via exploration and exploitation of entrepreneurial opportunities (Bienkowska et al. 2016; Bramwell and Wolfe 2008; Guerrero and Urbano 2012). This cluster focuses on understanding the nature and key activities of an entrepreneurial university, especially after the inclusion of the third mission, to engage in research commercialization, besides education and research activities (Galan-Muros et al. 2017). For instance, following the latest institutional and regional policy developments, entrepreneurial universities are encouraged to prioritize the following goals: development of entrepreneurial competencies by attracting and educating human capital, engagement in technology transfer and innovation as well as engagement in social and regional developments (Secundo et al. 2016). To attain these goals, entrepreneurial universities are expected to perform a list of activities, such as creation of technology parks, USO development, patenting/licensing, contract research activities, industry training, consulting, grant acquiring, research, and education (Philpott et al. 2011). 


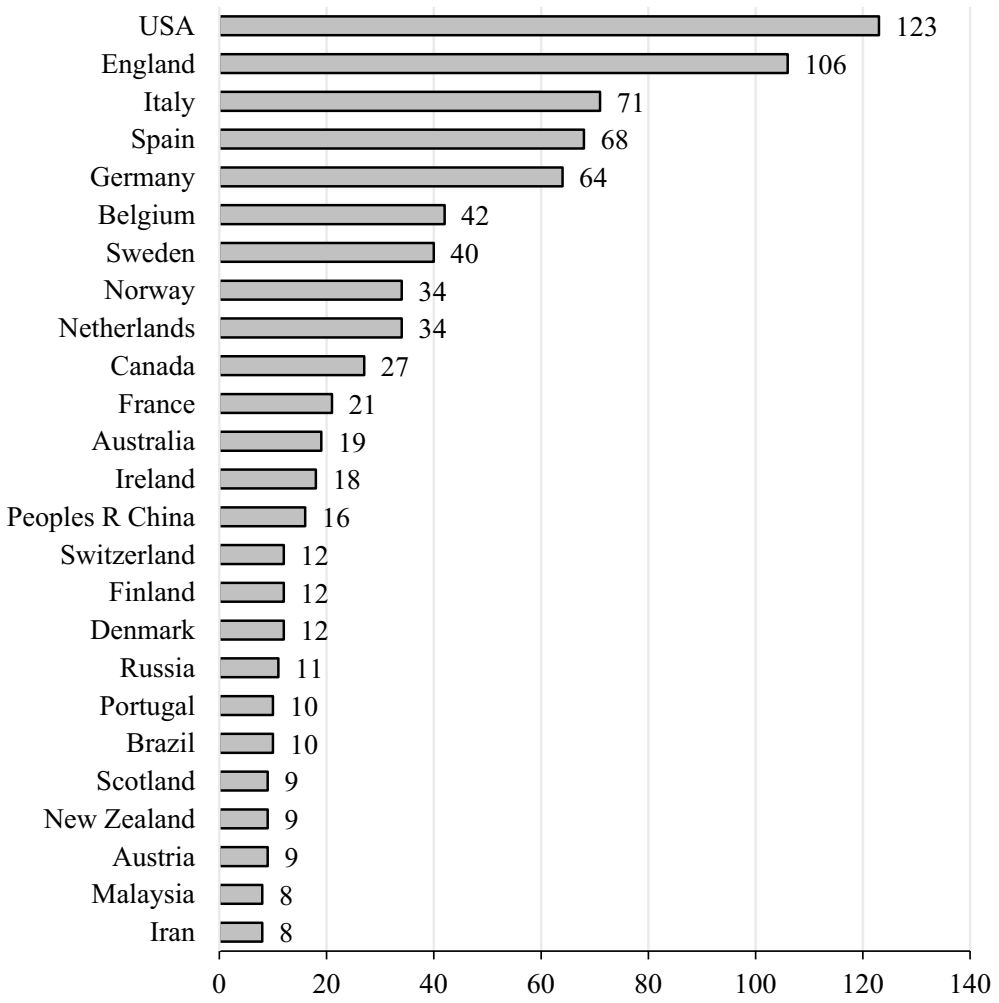

Fig. 6 Distribution of author country affiliations in selected publications (top 25 countries)

Further, another articles substream addresses the development of entrepreneurial universities. It is recognized that universities are embedded in multilayered systems and several hierarchical levels - from colleagues and supervisors, to research groups and departments, to faculties and central administrations. To develop into entrepreneurial universities and to avoid any potential barriers, universities are expected to design long-term strategies and obtain support at all levels, to attain the entrepreneurial goals and make new economic and societal impacts (Bienkowska et al. 2016; Galan-Muros et al. 2017).

Another substream of high interest that relates to the publications on entrepreneurial universities is the assessment of the impacts generated by entrepreneurial universities' activities. Among the noted activities, entrepreneurial universities can function collaboratively on a regional level, and can therefore support new venture formation and growth in a region by stimulating tacit knowledge-sharing among networks of innovative firms, and can engage in a virtuous cycle of talent attraction and retention (Bramwell and Wolfe 2008; Guerrero and Urbano 2012). Thus, it is necessary to develop new metrics that would allow us to estimate the generated value and economic and societal value at the regional and national levels.

This cluster generally addresses the issue of entrepreneurial university development, emphasizing the importance to identify the factors that stimulate entrepreneurial activities among academic institutions, as well as the potential barriers that may hinder further entrepreneurial initiatives. Special attention is devoted to channels of research 


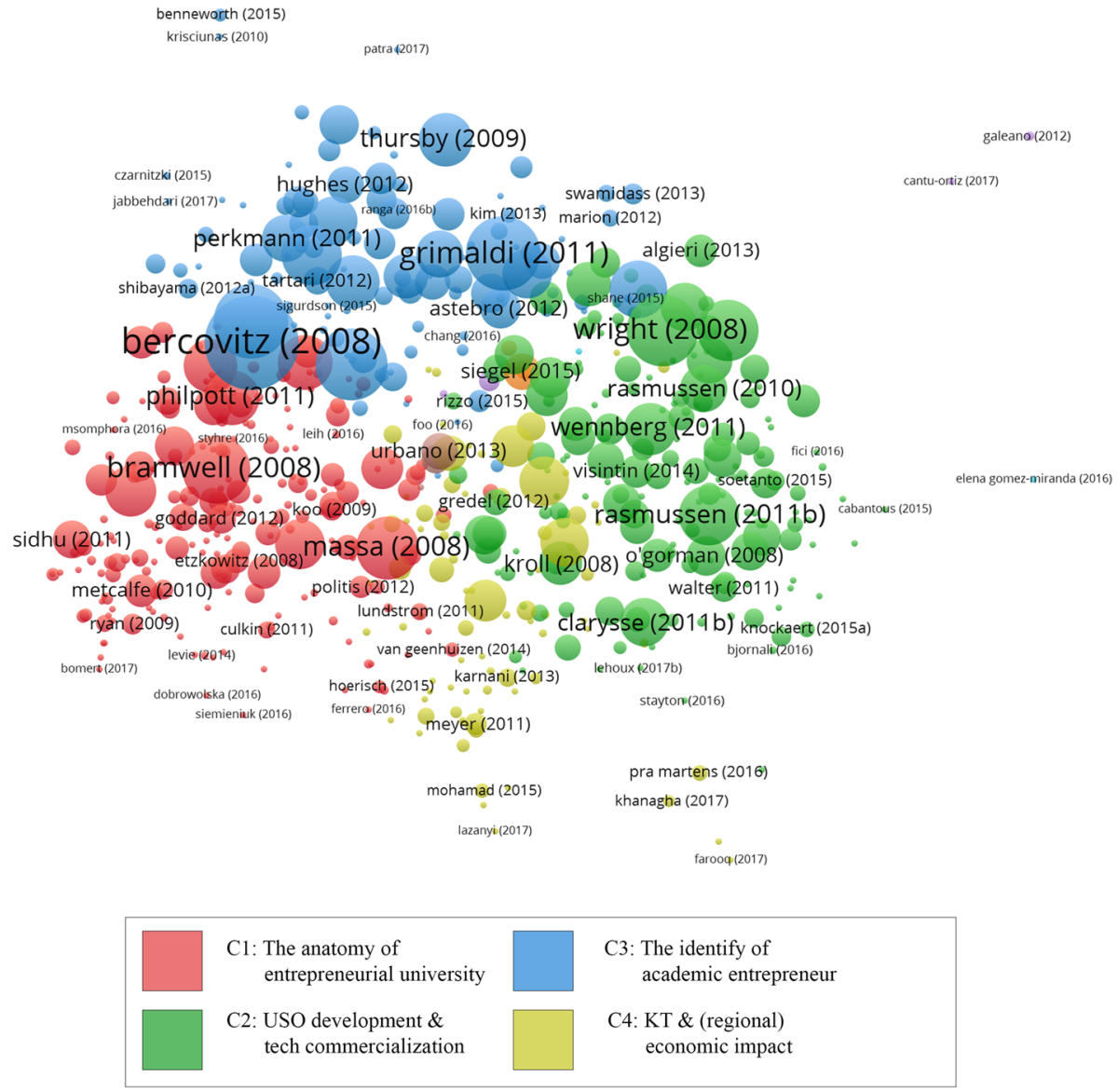

Fig.7 A visualized bibliometric network of clustered articles included in the dataset, based on bibliographic coupling (red items represent cluster 1 , green items cluster 2, blue items cluster 3, and yellow items cluster 4). (Color figure online)

commercialization dependent on regional institutional differences and the effects of recent policy developments.

\section{Cluster 2: university spinoff development and technology commercialization}

According to Figs. 10 and 11, this cluster focuses on USO creation as well as knowledge and technology commercialization activities. The research in this cluster focuses on examining dynamic USO development process and the necessary determinants to overcome the critical junctures to reach the sustainable returns stage (Rasmussen et al. 2011).

A notable number of publications report that many USOs show limited growth and development, or even failure in the early stages of new venture creation (Fini et al. 2017). Thus, a key discussion thread on USO development is identifying USO determinants and potential success factors (Fisher, Kotha, and Lahiri 2016; Perkmann et al. 2013). However, to determine what drives successful USOs, one must understand these 


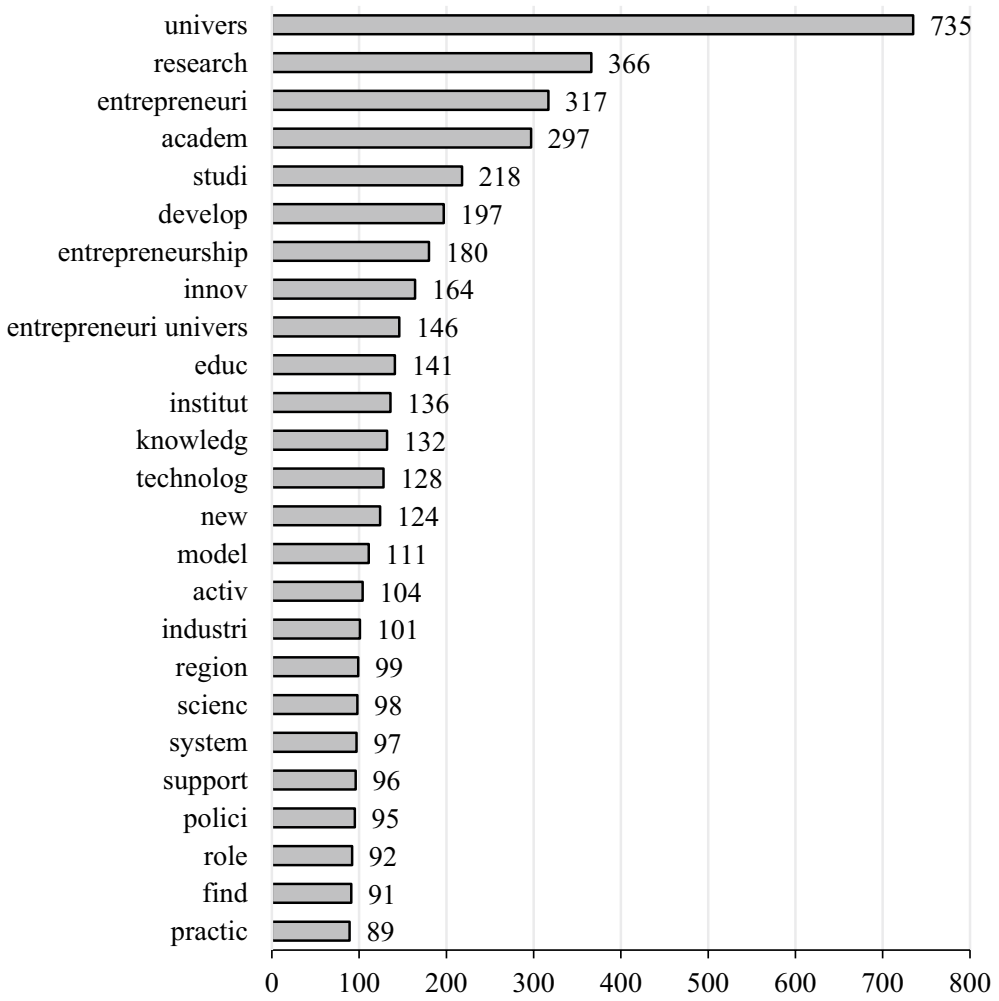

Fig. 8 Distribution of the most frequent terms in cluster 1, based on the bibliographic coupling's results

ventures' entire lifecycle. Thus, it is necessary to draw on Vohora et al. (2004) seminal work. Although the latter paper falls outside the scope of this bibliometric literature review, it provides a fundamental basis for many conceptual frameworks presented in articles that are included in our dataset. Thus, according to Vohora et al. (2004), USO development has five distinct phases: (1) the research phase, (2) the opportunity framing phase, (3) the pre-organization phase, (4) the re-orientation stage, and (5) the sustainable returns phase. Every phase has a specific activities set and a strategic focus that the venture must accomplish before transitioning into the next development phase. However, to pass through these phases and become an established firm in the market with sustainable returns, a USO venture must undergo the transitions referred to as critical junctures. These are complex problems that "occur at a point along a new high-tech venture's expansion path preventing it from achieving the transition from one development phase to the next" (Vohora et al. 2004, p. 159). They identified four critical junctures: (1) opportunity recognition, (2) entrepreneurial commitment, (3) venture credibility, and (4) venture sustainability.

The main thematic areas in the cluster on USOs and technological commercialization can be attributed to these five USO venture development phases and overcoming various problems associated with critical junctures. Thus, to successfully develop a USO, one must recognize that this is a dynamic - and more importantly, multistage-process that requires different knowledge and various resources, depending on the USO's 


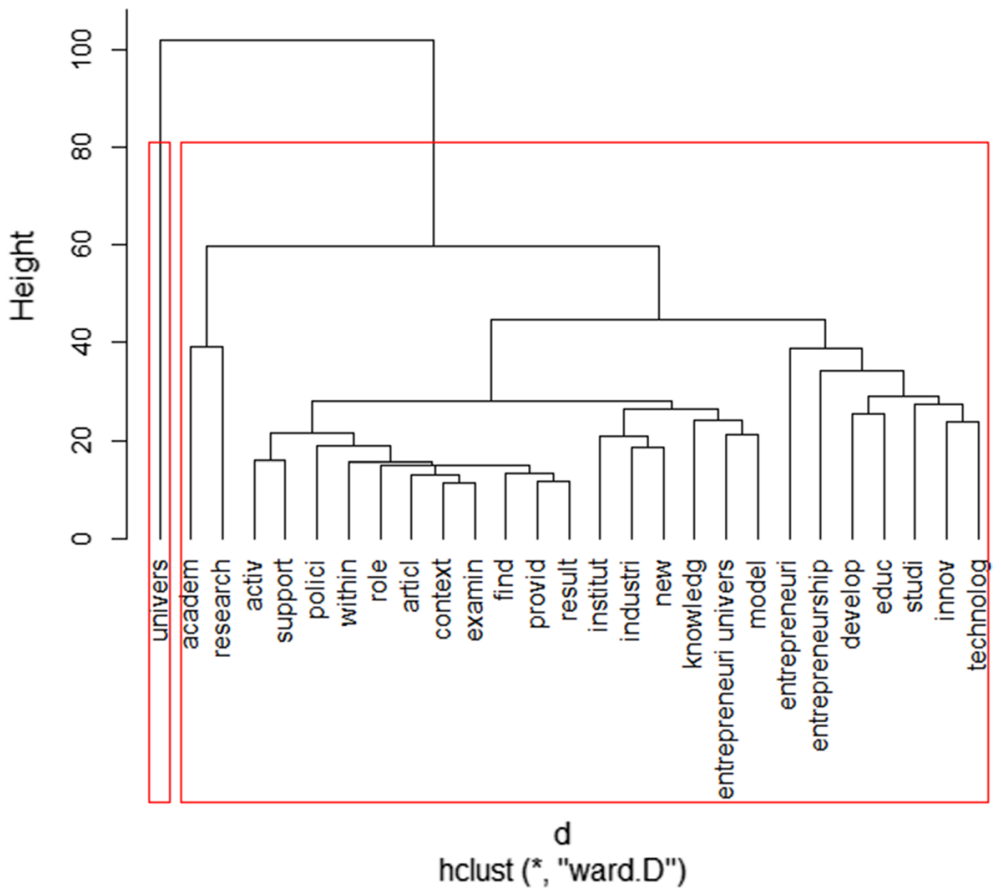

Fig. 9 Visualized Cluster 1 dendrogram of the key terms, based on the Euclidean distances (height) and Ward.D method

development phase, and requires specific short-term and long-term evaluation criteria (Clarysse et al. 2014). This is addressed by a large portion of publications in this cluster.

Another substream relates to the venture credibility juncture (Vohora et al. 2004). It is crucial for a USO to gain access and acquire initial resources for successful USO development in its nascent development stage. Rasmussen et al. (2011) identified leveraging competency, besides the opportunity refinement and championing competencies necessary to undergo the necessary USO development phase transitions. Leveraging competency refers to the ability to acquire and combine resources to maintain the venture creation process (Rasmussen 2011; Rasmussen and Borch 2010; Rasmussen and Wright 2015). An important part of the literature on USOs focuses on funding as a source to reach the credibility threshold and to overcome the liabilities of both smallness and newness (Fisher et al. 2016) In the literature, there is a distinction between funding sources. Some publications address governmental initiatives and policy development to support academic entrepreneurship, while others address the venture capitalist literature (Franke et al. 2008; Islam et al. 2018).

Also, a broader publications thread address the roles of the environment and the context a USO is embedded in. For instance, a list of publications explores the impacts of conflict resolution policies between the parent university and the USO venture, as well as IP management quality (Muscio et al. 2012, 2016). The same importance is allocated to studies that examine the impacts of the quality of universities, departments, and colleagues, as well as the USO venture team's composition and its experience of successful USO development (Tartari et al. 2014; Van Looy et al. 2011). 


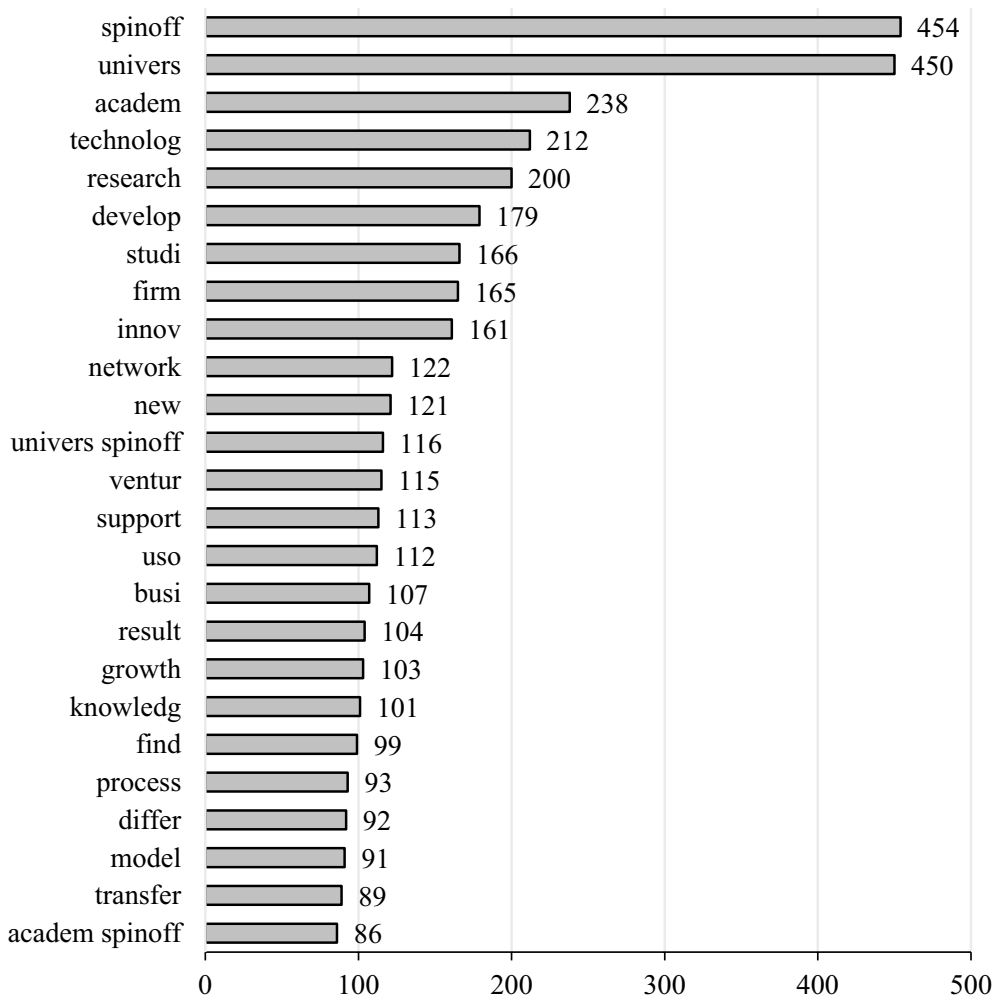

Fig. 10 Distribution of the most frequent terms in cluster 2, based on the bibliographic coupling's results

\section{Cluster 3: identity of academic entrepreneurs}

According to Figs. 12 and 13, this cluster addresses the academic entrepreneurship process and technology/research commercialization by academics and/or scientists. The second identified subtheme highlights the roles of various elements such as industry, policy developments, and individuals in the knowledge and technology transfer process. Thus, this cluster focuses on examining the identities and roles of academic entrepreneurs.

The research in this cluster is located at the individual level. This makes sense, since academic entrepreneurial behavior occurs at the interface of an opportunity and an individual, with heterogeneity existing on both the individual and the opportunity sides. Here, the central research focus is on the characteristics of academic entrepreneurs as they engage in the entrepreneurial process, and especially on the mechanisms that foster such academics entrepreneurial identities.

Specifically, research in this cluster focuses on analyses of the links between these academics' latent entrepreneurial skills, abilities, experience, attitudes, perceived norms, and intentions to create a spinoff (D'Este et al. 2012). The analysis of academic entrepreneurs' identities is in line with Vohora et al. (2004) conceptual framework, introduced in the previous section. According to Rasmussen et al. (2011), to successfully pass through the critical junctures and develop a USO venture into a stable market player, academic entrepreneurs must possess three entrepreneurial competencies. 


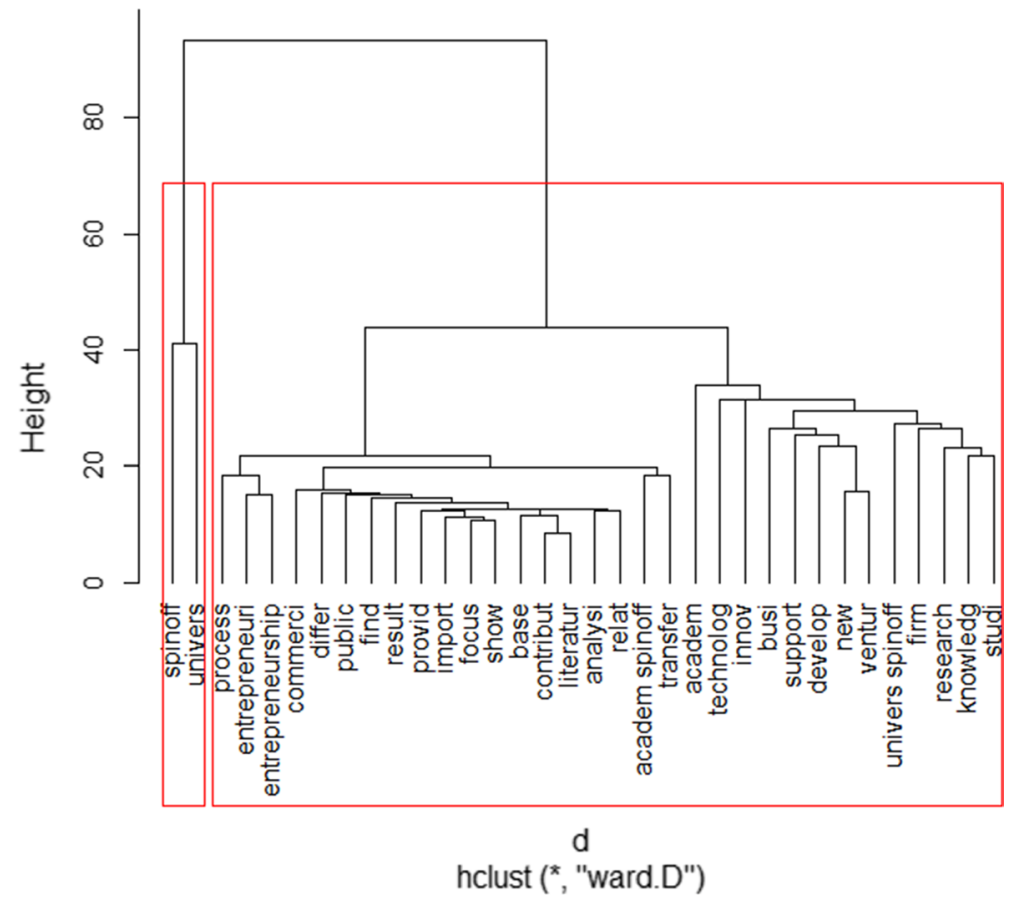

Fig. 11 Visualized cluster 2 dendrogram of the key terms, based on the Euclidean distances (height) and Ward.D method

Leveraging competency has already been discussed. In the context of examining academic entrepreneurs' identities, opportunity refinement competency and championing competency are interesting to study in depth. Opportunity refinement competency generally refers to the ability to discover opportunities based on scientific research results, and to further develop these into viable business concepts. Championing competency refers to the ability to identify with a venture and to persuade others to contribute to its development. These two entrepreneurial competencies are crucial for successful academic entrepreneurs.

In line with this argument, it could be stated that academic entrepreneurs' ability to detect technological opportunities is attributed to different scientific skills sets and expertise, compared to the ability to exploit these entrepreneurial opportunities. Academic entrepreneurs' research excellence and previous experience of discovering technological opportunities would more likely foster the detection of new technological opportunities. In comparison, previous collaboration with industry partners, scientific breadth, and commercially oriented experience would stimulate the exploitation success of technological opportunities (D'Este et al. 2012).

In addition to predicting the likelihood of becoming an academic entrepreneur based on for instance their opportunity recognition ability and prior entrepreneurial experience, the process of transitioning from the scientist role into the academic entrepreneur role is increasingly explored. Thus, a related thematic publication area in this cluster addresses the importance of researchers personal identities in the academic environment and the commercial business environment (Jain et al. 2009). In the process of academic 


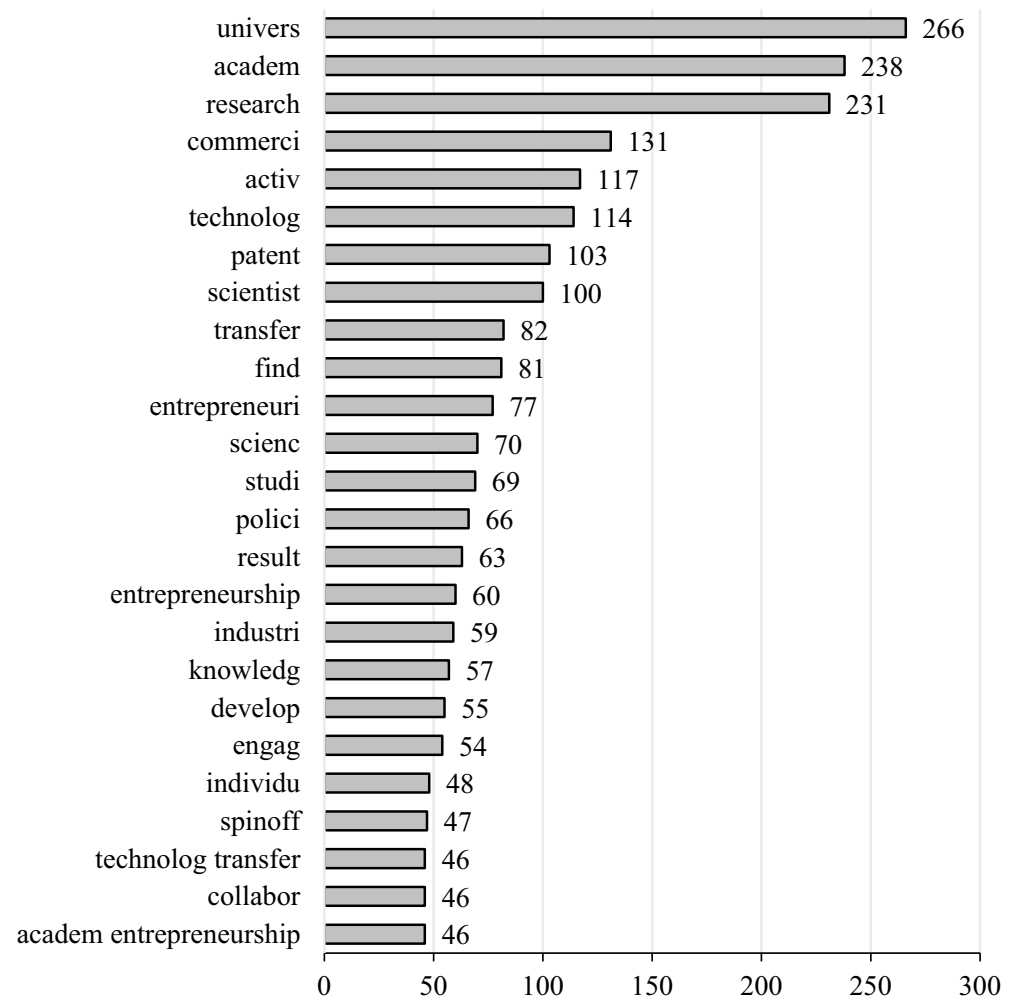

Fig. 12 Distribution of the most frequent terms in cluster 3, based on the bibliographic coupling's results

entrepreneurship and USO venture development, academics may have a tendency to maintain the hierarchy from their academic environment, while USO development requires a different level of personal communication and interconnections. A specific subtheme of this cluster addresses this issue, and examines the roles of personal networks and embedded hierarchies in USO development success.

Also, an academic entrepreneur's environment shapes their extent of engagement in entrepreneurial activities and their preferred channels of engagement (Bercovitz and Feldman 2008; D’Este and Perkmann 2011; Perkmann et al. 2013). Academic entrepreneurs tend to more actively engage in entrepreneurial activities if the parent institution sufficiently supports possibilities and has developed norms that stimulate such activities. A connected research focus in this cluster is the roles of business incubators and science parks regarding facilitating the development of academic entrepreneurs, both among experienced researchers and young academics or even students.

\section{Cluster 4: knowledge transfer and (regional) economic impacts}

According to Figs. 14 and 15, this cluster addresses academic entrepreneurship from a broader perspective, focusing on describing the entrepreneurial processes via knowledge and technology transfer, and highlighting the roles of entrepreneurial academic institutions, researchers, and young graduates as ways to generate new economic value. 


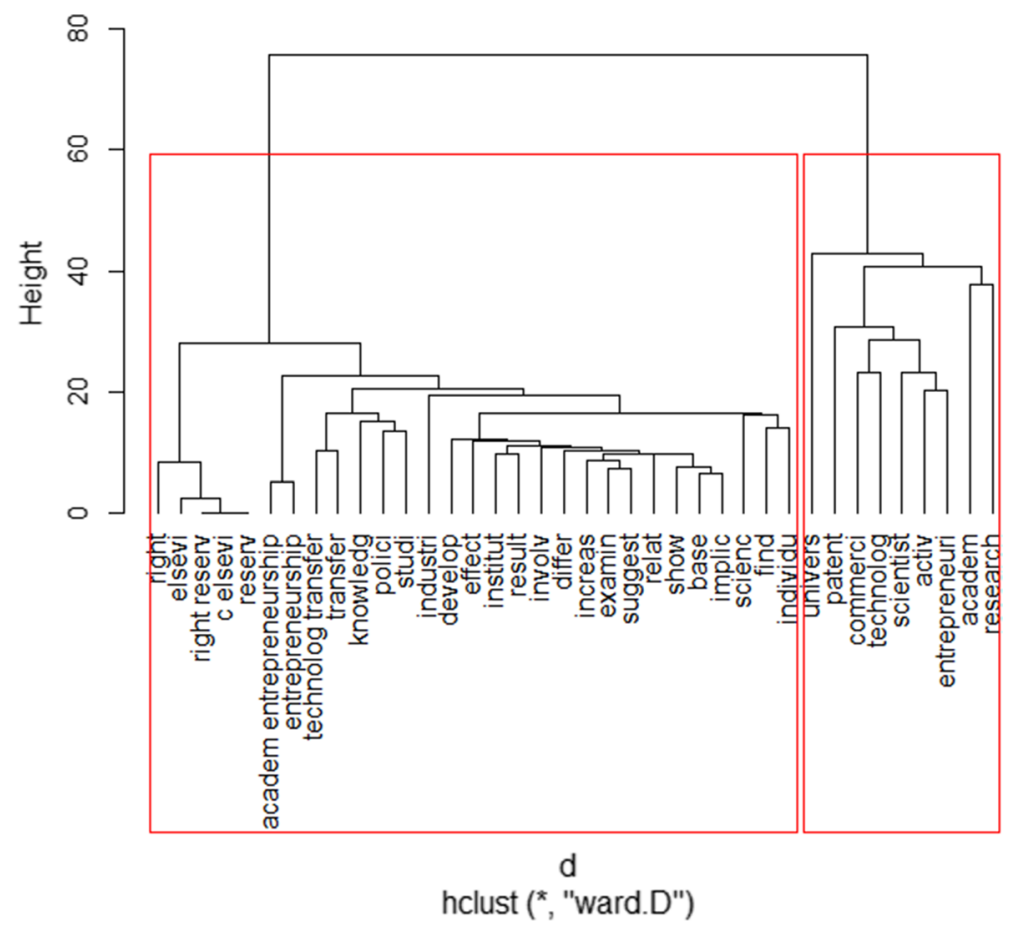

Fig. 13 Visualized cluster 3 dendrogram of the key terms, based on the Euclidean distances (height) and Ward.D method

This cluster centers around the analysis of academic entrepreneurship as a catalyst for regional economic and societal developments via knowledge transfer and USOs. Thus, it addresses academic entrepreneurship from the perspective of an ecosystem consisting of individual, organizational, and institutional elements. Specifically, this cluster emphasizes the changed roles of academic entrepreneurship and entrepreneurial universities (Audretsch 2014). The roles of universities in an increasingly entrepreneurial society have broadened, and in addition to the need to generate technology transfer and knowledge-based USO ventures, academic institutions are focused on enhancing entrepreneurship capital and stimulating behavior to prosper in an increasingly entrepreneurial society (Audretsch 2014; Audretsch et al. 2014).

By distinguishing between two dimensions of the academic entrepreneurship context, the task environment and the non-task environment, it is possible to further nuance this research cluster's focus. Research into academic entrepreneurship's task environment explores the quality and effectiveness of universities, faculties, departments, and TTOs concerning supporting and stimulating academics' entrepreneurial competencies. For instance, Muscio et al. (2016) identified three classes of institutionally defined rules that should be considered as an effective incentive to help faculty members to create USO ventures: (1) general rules and procedures, (2) rules regulating monetary incentives, and (3) rules that affect entrepreneurial risk.

The research at the level of the non-task environment examines institutional factors that affect academic entrepreneurship at regional and national levels, such as the extent 


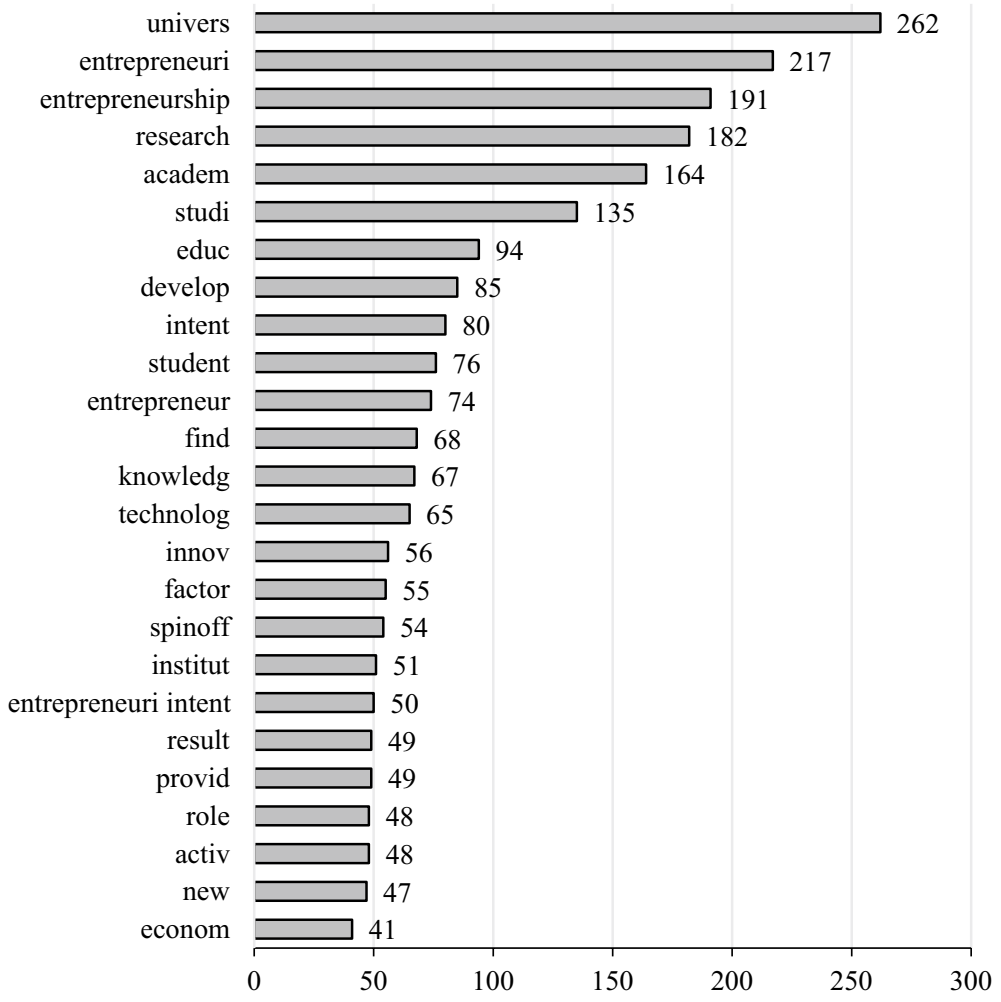

Fig. 14 Distribution of the most frequent terms in cluster 4, based on the bibliographic coupling's results

of government support. For instance, governments and universities have proposed relevant initiatives aimed at fostering academic entrepreneurship, such as legislative changes, government support schemes, university policies, technology transfer offices, entrepreneurial training, and education for staff and PhDs students (Bienkowska et al. 2016). The alignment between these two foci can be established by developing interaction and knowledge exchange channels as well as support mechanisms.

The fundamental notion of the research in this cluster is the broad, far-reaching scope of influence of academic entrepreneurship (Gerbin and Drnovsek 2016; Guerrero et al. 2016). Here, academic entrepreneurship is seen as a tool that goes beyond pure business and commercialization aspects-i.e. also having societal impacts; for instance, through the creation of new products and services that improve quality and convenience while reducing costs, academic entrepreneurship can prevent healthcare crises (Itri et al. 2015). Thus, researchers are investigating how academic entrepreneurship can promote economic and societal developments across the world, as well as the potentially facilitating and hindering factors.

To support qualitative analysis of the bibliographic coupling's findings, I provide an additional statistical overview. Figure 16 illustrates the evolution of the academic entrepreneurship literature based on the identified clusters, employing bibliographic coupling. Table 1 summarizes the identified clusters' main statistical details.

The statistical comparison indicates different evolution patterns of identified clusters, as well as their importance, based on the number of publications and received citations. 


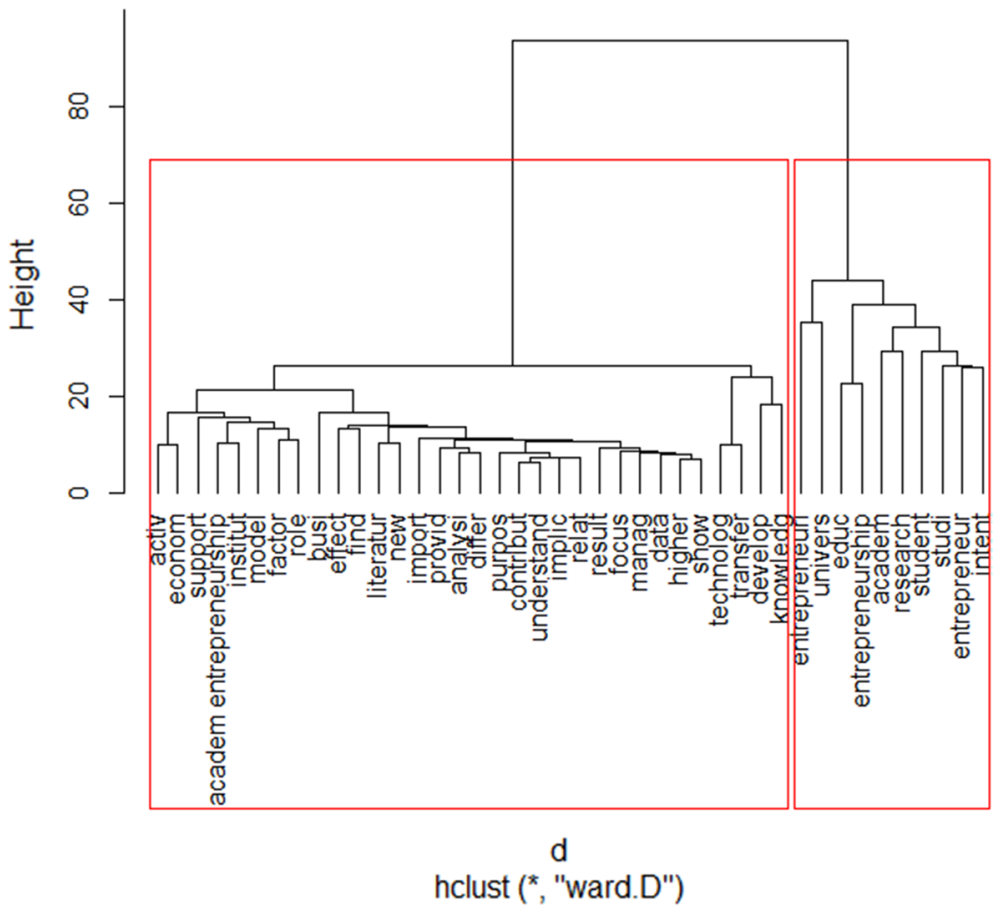

Fig. 15 Visualized cluster 4 dendrogram of the key terms, based on the Euclidean distances (height) and Ward.D method

Figure 16 shows that all four identified clusters have developed and have received substantial acknowledgment in research. The overall trend is positive, showing that the academic entrepreneurship literature has experienced expanded greatly in the past 5 years, starting from 2013. Notably, between 2008 and 2013, the academic entrepreneurship research field remained relatively neglected. Next, it is possible to observe differences between the identified clusters' evolution patterns. The knowledge transfer and regional economic impacts cluster (Cluster 4) has expanded significantly and is still actively developing. While the entrepreneurial university cluster (Cluster 1) experienced a strong increase between 2014 and 2015, it has leveled off in the past 2 years. A similar pattern, but with smaller numbers of related publications, can be associated with Cluster 2, which focuses on USOs and technological commercialization. The research into entrepreneurial identities has remained fairly stable, with some negative developments in the past 2 years.

Table 1 provides a statistical comparison of the key indicators for the identified clusters. Compared to the evolution patterns displayed in Fig. 16, some notable differences in the clusters' relative importance can be observed. While Cluster 1 (on the anatomy of an entrepreneurial university) had the highest number of publications, the citations were relatively low compared to the clusters on USO development and the identities of academic entrepreneurs. To some extent, this implies the current trend and popularity of this research domain. These findings signal that there is an increasing trend of publications, while the papers' impacts have not yet fully accumulated. Compared to Cluster 3 (on the identity of academic entrepreneur), the publication number is lower, while the average citations per 


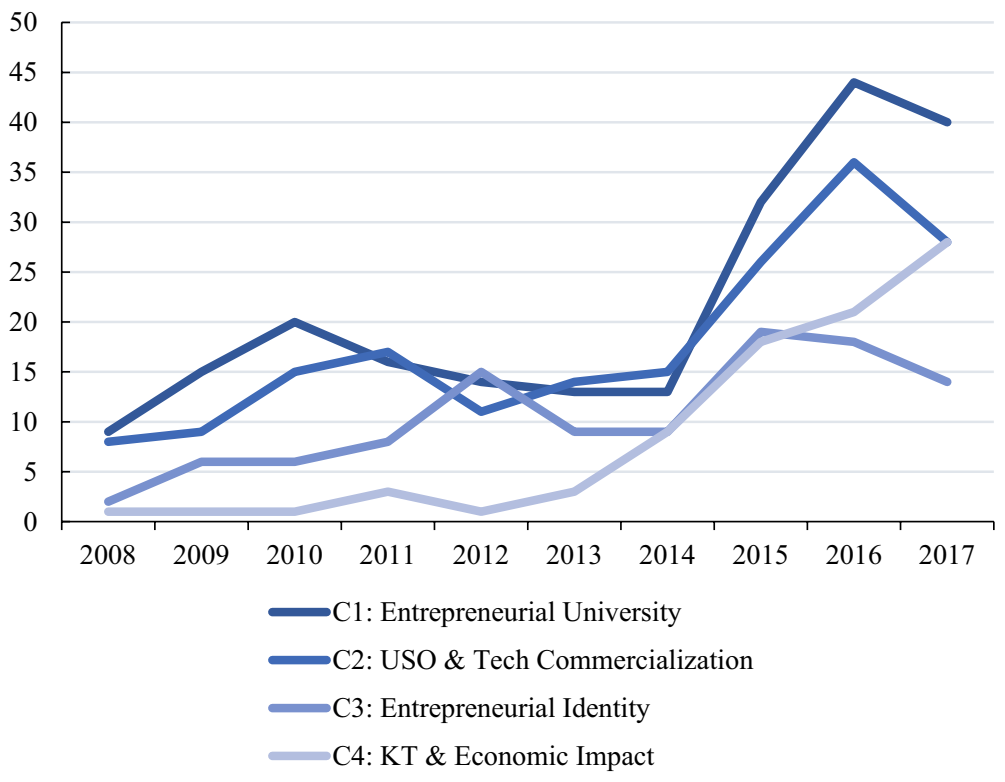

Fig. 16 Distribution of WOS publications on academic entrepreneurship between 2008 and 2017, per the four identified clusters, based on the bibliographic coupling's results $(n=587)$

publication are the highest in the academic entrepreneurship literature. This signals that this research domain has evolved into a stable thematic area that includes various influential seminal papers. This implies that the main characteristics of academic entrepreneurs are well-researched and that most academic entrepreneurship authors are now focusing on other research domains. Compared to the abovementioned clusters, Cluster 2 (on USO development and tech commercialization) has maintained a stable development pattern, and has solid relevance in the academic entrepreneurship research field. Finally, Cluster 4 and the knowledge transfer and regional economic impacts research fields showed the lowest numbers, which is in line with Fig. 16. This confirmed the previous argumentation that entrepreneurial universities are developing and that the importance of entrepreneurial activities is increasingly being acknowledged. Table 1 shows that the publications in this cluster were the most recent, on average, published mainly in the past 2 to 3 years. This also explains the low number of citations, indicating that while this research domain in academic entrepreneurship is peaking, it has not yet reached maturity, and more research of this nature is expected in the near future.

\section{Discussion and future research agenda}

I have responded to calls to synthesize the latest developments in the academic entrepreneurship literature and to come up with an informed roadmap that stimulates relevant and interesting future research (Bozeman et al. 2013; Rothaermel et al. 2007; Siegel and Wright 2015). I conducted a comprehensive quantitative analysis of the evolution of the academic entrepreneurship literature, carving out established themes. Further, I will consolidate 


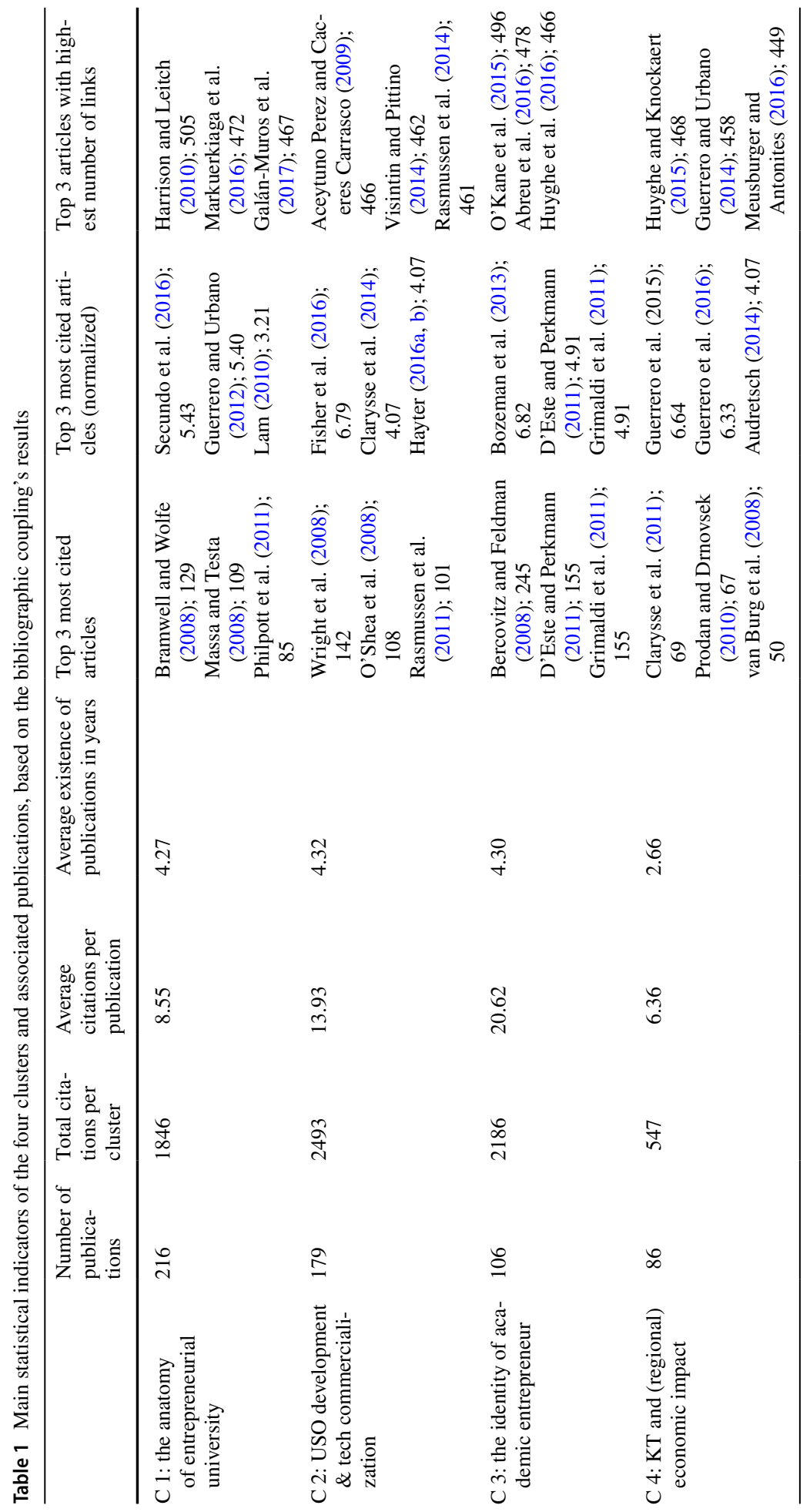


these findings with the emerging trends indicated by the bibliographic coupling's results. Generally, the results suggest that there are four thematic clusters, which should draw interest from researchers, university managers, practitioners involved in collaborative activities, and policymakers.

The findings of this paper indicate that the academic entrepreneurship research field can be analyzed from the perspective of four interconnected elements: (1) the entrepreneurial university, (2) USOs, (3) academic entrepreneurs, and (4) the entrepreneurial environment in which all these elements are embedded in order to transfer the knowledge and technologies developed at the parent university, as well as to commercialize the research outcomes to stimulate regional economic and societal development. Specifically, the bibliometric literature analysis results indicate that this research domain can be linked within the academic entrepreneurship ecosystem. The results are in line with previous research, and indicate that academic entrepreneurship is a dynamic, multilayered ecosystem with actors at the individual, organizational, and institutional levels (Audretsch et al. 2019; Guerrero and Urbano 2012; Harrison and Leitch 2010; Hayter et al. 2018; Miranda et al. 2018; Perkmann et al. 2013).

Concerning the individual level, this paper has addressed academic entrepreneurs' identities and has explored the characteristics that drive the researchers' entrepreneurial intentions and external determinants that either facilitate or hinder entrepreneurial activities. However, further research is needed to nuance our understanding of how psycho-social characteristics shape academic entrepreneurs' behavioral intentions (Clarysse, Tartari, and Salter 2011; Goethner et al. 2012). A very promising research avenue would be to focus on the identity struggles academics experience when engaging in entrepreneurship (Bozeman et al. 2013; Jain et al. 2009). Since entrepreneurial identity could also be shaped by external factors, future research could investigate the policy developments and university governance modes that have the potential to stimulate innovations among academics (Astebro et al. 2012). Further, and generally, the entrepreneurial process is considered to make high demands of every individual entrepreneur (Hatak et al. 2015), and this process may be exacerbated in hybrid academic entrepreneurship, with the academic entrepreneur working for both the university and their own business, which may affect their identity struggles and wellbeing levels. In a similar vein, there is a lack of studies investigating the role of individual psychological attributes such as risk tolerance and ambiguity on the academic entrepreneurs' ability to discover technological- and exploit the entrepreneurial opportunities (D'Este et al. 2012). Similarly, individual incentives and motivations determining the primary engagement channels (e.g. patenting, USO creation, joint research, contractual research, consultancy) of academic entrepreneurs and the related business outcomes require further investigation (D'Este and Perkmann 2011). Another auspicious direction for future research focuses on development of academic spin-off ventures by nascent academic entrepreneurs and the need to acquire or develop entrepreneurial competencies (see e.g. Oosterbeek et al. 2010; Rasmussen et al. 2011, 2014). While prior studies have investigated the importance of entrepreneurial competencies on venture performance, more insights are necessary to examine development processes of the entrepreneurial competencies and potential inhibitors on individual, organizational and institutional levels (Gümüsay and Bohné 2018), calling for in-depth qualitative and quantitative examination, especially regarding the competencies required in the different academic entrepreneurial lifecycle stages (Clarysse et al. 2011; Rasmussen et al. 2014) as well as meta-analyses.

At the organizational level, I examined the roles of entrepreneurial universities and USOs, which are considered effective tools for research commercialization. The findings present a list of activities undertaken by entrepreneurial universities and the role of the 
university's third mission evolution. I also presented the USO development phases and the necessary transitions in order to reach sustainable returns.

From the entrepreneurial university perspective, the findings of the bibliometric analysis signal the need for a more in-depth understanding of the role of entrepreneurial university in the entire ecosystem of academic entrepreneurship and its related contributions. More specifically, future studies should address the processes associated with the development of strategies, structures, and culture that strengthen an entrepreneurial university, supported by specialized education and training as a flourishing field for progress (Guerrero and Urbano 2012). Additionally, a vital research direction calling for future studies focuses on a development of effective support mechanisms and strategic decisions in entrepreneurial universities fostering academic entrepreneurship. For instance, there is a lack of studies addressing the impact of strategic choices regarding the type of support for university spinoffs and student/young graduate start-ups, and more deeper investigation of university's entrepreneurial mission determining the level of support and entrepreneurial outcomes (Marzocchi et al. 2017). Another promising avenue for future studies addresses the impact and effectiveness of TTO's. Thus, understanding not only the resulting outcomes of TTO' engagement, but also learning about the reasons why academic ventures bypass a local TTO, how often, and what are the consequences of such decision is of critical importance (Huyghe et al. 2016). Next to that, future studies should investigate the interaction of different hierarchical levels of university support for academic entrepreneurship (i.e. from supervisor and colleagues, to research groups and departments, and finally to faculty to central administration) (Bienkowska et al. 2016) in order to design enhanced support systems for academic entrepreneurship.

From the USO perspective, more in-depth research is needed to understand why many USOs cannot overcome the liability of newness and smallness and fail at the early stage, or remain small and do not generate the expected returns, despite the availability of support mechanisms on university and policy levels (Fini et al. 2017; Fisher et al. 2016; Hesse and Sternberg 2017). To tackle this major research problem, several research directions need to be highlighted. For instance, further analysis is necessary concerning the interplay between the availability of resources and specific goals of potential entrepreneurial endeavors (Bozeman and Boardman 2013; Rasmussen et al. 2014). In the context of USOs, further research is needed to determine the key differences in necessary tangible and intangible resources at different USO development stages (Rasmussen and Wright 2015). Furthermore, an important set of research questions relates to the link between the USO and competence creation processes. Building and extending the research by Danneels (2002, 2008), scholars could further improve the understanding of how competence creation processes differ among USO types (Colombo and Piva 2012). For instance, scholars may want to understand how different USOs develop their competences, how they shape and define the strengths of their firms, and how USOs renew their existing competences. Another research question relates to the heterogeneity of USO outcomes that are achieved by USOs with different competence portfolios. Here, scholars could focus on how different USOs in terms of their competences shape growth in both the business sphere and the academic sphere. Next to that, studies focusing on network analysis in the context of academic entrepreneurship will form an important future research stream. Specifically, more research can be conducted into the importance of network centrality and the role of structural holes in relation to various business outcomes (Diez-Vial and Montoro-Sanchez 2017), but also into the evolution of social networks among faculty and graduate student entrepreneurs and the role of knowledge intermediaries therein to compare USO success leveraged by academic and non-academic contacts (Hayter 2016a, b). 
Nevertheless of the increasing number of studies addressing the success factors of USOs and early assessment of USO business potential, there is a lack of in-depth studies addressing the complex process of USO project evaluations in terms of financial support by means of public and non-public funding (Kim et al. 2019). Thus, a promising future research avenue would be to examine factors determining a positive funding outcome and processes driving evaluator decisions. Another worthwhile future research focus is the systematic evaluation of failed academic entrepreneurship projects and collaborations, in conjunction with the (lack of) support from the university, which could reveal new success factors (Bozeman et al. 2013), besides tackling the success bias in entrepreneurship research generally.

Further, additional research is needed into the impacts of student and young graduate entrepreneurship and their ventures, which constitutes an emerging source of discontinuous innovations (Astebro et al. 2012; Siegel and Wright 2015). Students and young graduates not only form a driving force of academic spin-off establishment, but also are able to connect other academic entrepreneurs to academic and non-academic contacts from previous entrepreneurship programs, events, and experiences. Thus, more research is needed exploring the contributions of student- and graduate-led ventures, as well as their strengths and weaknesses (Hayter 2016a, b). In order to grasp the various effects of entrepreneurial universities and academic ventures, additional research is necessary to develop new short-term and long-term success indicators, such as citation impact to include quality measure, and IPO, profitability, sustainable growth to include economic indicators. This is relevant for assessing the impact of governmental support mechanisms, and improvement of early-stage investment decision making, as well as further assessment by venture capitalists (Clarysse et al. 2014).

At the institutional level, I have addressed the increasing importance of academic entrepreneurship and universities' evolution from education-oriented to more entrepreneuriallyoriented institutions. I have addressed the process of knowledge and technology transfer and the related entrepreneurial environment in the research institutions, and acknowledge the potential to generate new economic and societal value.

At the institutional level, governmental authorities and universities should collaborate to ensure consistent support during various academic entrepreneurship stages. However, more research is needed to help us to understand the challenges of setting up such collaborative agreements between academic and institutional actors, and the critical mechanisms for the governance and sustainability of such networks to establish an entrepreneurial environment (Audretsch et al. 2019). Specifically, future studies should focus on institutional differences' roles in terms of multiple dimensions such as regulative, normative, and cultural institutions for academic entrepreneurship, and should explicitly address the interactions between nested variables (Bozeman et al. 2013), and ensure distributed value creation for economic, technological and societal benefits. Furthermore, it is worthwhile to examine to what extent is it possible to replicate such ecosystems in different environments (Audretsch et al. 2019). Also, we need a greater emphasis on contextual dynamism, in terms of legislative and institutional changes (Fini et al. 2011). Here, historical and multidisciplinary research approaches are required. Since the vast majority of the research into academic entrepreneurship has been conducted in developed economies, future research should explore its effectiveness concerning stimulating economic and societal development in emerging countries (Gonzalez-Pernia et al. 2013). In particular, future studies could examine various modes of interaction, the kind of knowledge and resources shared between universities and firms, and the outcomes generated from these interactions in developed countries (Zavale and Langa 2018).

Here, and in line with the research directions proposed by Siegel and Wright (2015), I recommend broadening the focus to new forms of academic entrepreneurship, 
including social and green/clean academic entrepreneurship (Colombelli and Quatraro 2019; Doblinger et al. 2019). A promising line of research could be to explore the impact of accelerating clean energy and green technology innovations to mitigate climate change and enhance competitiveness of advanced countries by designing new policies on university- and institutional levels. Further, to enable the generation and comparability of substantial findings on academic entrepreneurship that can inform policymakers' decisions, future research should develop and use advanced metrics that enable capitalization on academic entrepreneurship as a tool to strengthen regional/national economic and societal development (Bozeman and Boardman 2013; D’Este et al. 2018; Siegel and Wright 2015).

\section{Limitations and future research avenues}

While this bibliometric literature analysis has presented a list of important findings, it has limitations, which provide future development areas. First, I have covered a broad scope of academic entrepreneurship literature based on a specific search query that enabled me to highlight key elements of this research field. However, including additional keywords in a search query could lead to the development of a more comprehensive dataset and, thus, to additional empirical insights. Second, the constructed dataset had a scope of 10 years. Experimenting with additional time periods can lead to the identification of additional articles, especially potentially seminal work on academic entrepreneurship, and can therefore present additional perspectives. Similarly, since the main goal was to build on the literature to identify current themes and emerging trends, bibliometric analysis is restricted to the bibliographic coupling technique. Thus, extending results with co-citation analysis, co-occurrence analysis, and other quantitative literature review methods can provide additional insights and key elements on the path to developing a comprehensive understanding of the academic entrepreneurship ecosystem. Finally, further research can significantly benefit from application of advanced computational methods. For instance, topic modelling and other unsupervised machine learning methods can improve the scope and level of bibliometric analysis in future studies.

\section{Conclusion}

This paper investigates the current state of the academic entrepreneurship research field and detects new emerging research patterns by employing both quantitative and qualitative methods of analyses. Specifically, by using bibliographic coupling technique, this paper consolidates the main research streams of the past 10 years and contributes new complementary insights into the understanding of the complex and inter-connected nature of the research field. By using text mining and hierarchical clustering technique, and content analysis to support the interpretation of the key findings, this paper responds to a call by Miranda et al. (2018) to integrate a combination of various analytical techniques to foster a further development of this research field.

Additionally, based on a comprehensive content analysis, this paper outlines a nuanced research agenda of new emerging trends with valuable implications for academics and policy makers. I hope this research agenda will spur more systematic and robust research encompassing the assessment of new interlinkages of under-explored determinants of academic entrepreneurship. New findings will be of critical importance to assess and facilitate 
further technological, economic, and societal advancements on regional, national, and international arena.

Acknowledgements I would like to thank Isabella Hatak, Kasia Zalewska-Kurek and Petra de Weerd-Nederhof for insightful comments and encouraging suggestions on the earlier versions of this paper, as well as participants of the 2018 IPDM conference in Porto for helpful discussions. The author also acknowledges the support of the University of Twente (BMS) Tech4People initiative.

Open Access This article is distributed under the terms of the Creative Commons Attribution 4.0 International License (http://creativecommons.org/licenses/by/4.0/), which permits unrestricted use, distribution, and reproduction in any medium, provided you give appropriate credit to the original author(s) and the source, provide a link to the Creative Commons license, and indicate if changes were made.

\section{References}

Abreu, M., Demirel, P., Grinevich, V., \& Karataş-Özkan, M. (2016). Entrepreneurial practices in researchintensive and teaching-led universities. Small Business Economics, 47(3), 695-717.

Aceytuno Perez, M. T., \& Caceres Carrasco, F. R. (2009). Elaborating a framework to analyse the university spin-off formation. Revista de Economia Mundial, (23), 23-51.

Astebro, T., Bazzazian, N., \& Braguinsky, S. (2012). Startups by recent university graduates and their faculty: Implications for university entrepreneurship policy. Research Policy, 41(4), 663-677.

Audretsch, D. B. (2014). From the entrepreneurial university to the university for the entrepreneurial society. The Journal of Technology Transfer, 39(3), 313-321.

Audretsch, D. B., Cunningham, J. A., Kuratko, D. F., Lehmann, E. E., \& Menter, M. (2019). Entrepreneurial ecosystems: economic, technological, and societal impacts. The Journal of Technology Transfer, 44(2), 313-325. https://doi.org/10.1007/s10961-018-9690-4.

Audretsch, D. B., Lehmann, E. E., \& Wright, M. (2014). Technology transfer in a global economy. The Journal of Technology Transfer, 39(3), 301-312.

Balven, R., Fenters, V., Siegel, D. S., \& Waldman, D. (2018). Academic entrepreneurship: The roles of identity, motivation, championing, education, work-life balance, and organizational justice. Academy of Management Perspectives, 32(1), 21-42.

Bercovitz, J., \& Feldman, M. (2008). Academic entrepreneurs: Organizational change at the individual level. Organization Science, 19(1), 69-89.

Bienkowska, D., Klofsten, M., \& Rasmussen, E. (2016). PhD students in the entrepreneurial universityperceived support for academic entrepreneurship. European Journal of Education, 51(1, SI), 56-72.

Bock, C., Huber, A., \& Jarchow, S. (2017). Growth factors of research-based spin-offs and the role of venture capital investing. The Journal of Technology Transfer. https://doi.org/10.1007/s10961-017-9635-3.

Boyack, K. W., \& Klavans, R. (2010). Co-citation analysis, bibliographic coupling, and direct citation: Which citation approach represents the research front most accurately? Journal of the American Society for Information Science and Technology, 61(12), 2389-2404.

Bozeman, B., \& Boardman, C. (2013). Academic faculty in university research centers: Neither capitalism's slaves nor teaching fugitives. Journal of Higher Education, 84(1), 88-120.

Bozeman, B., Fay, D., \& Slade, C. P. (2013). Research collaboration in universities and academic entrepreneurship: the-state-of-the-art. The Journal of Technology Transfer, 38(1), 1-67.

Bramwell, A., \& Wolfe, D. A. (2008). Universities and regional economic development: The entrepreneurial university of Waterloo. Research Policy, 37(8), 1175-1187.

Clarysse, B., Tartari, V., \& Salter, A. (2011). The impact of entrepreneurial capacity, experience and organizational support on academic entrepreneurship. Research Policy, 40(8), 1084-1093.

Clarysse, B., Wright, M., Bruneel, J., \& Mahajan, A. (2014). Creating value in ecosystems: Crossing the chasm between knowledge and business ecosystems. Research Policy, 43(7), 1164-1176.

Colombelli, A., \& Quatraro, F. (2019). Green start-ups and local knowledge spillovers from clean and dirty technologies. Small Business Economics, 52(4), 773-792.

Colombo, M. G., \& Piva, E. (2012). Firms' genetic characteristics and competence-enlarging strategies: A comparison between academic and non-academic high-tech start-ups. Research Policy, 41(1), 79-92.

Czarnitzki, D., Rammer, C., \& Toole, A. A. (2014). University spin-offs and the "performance premium". Small Business Economics, 43(2), 309-326. 
D’Este, P., Mahdi, S., Neely, A., \& Rentocchini, F. (2012). Inventors and entrepreneurs in academia: What types of skills and experience matter? Technovation, 32(5), 293-303.

D’Este, P., \& Perkmann, M. (2011). Why do academics engage with industry? The entrepreneurial university and individual motivations. The Journal of Technology Transfer, 36(3), 316-339.

D’Este, P., Ramos-Vielba, I., Woolley, R., \& Amara, N. (2018). How do researchers generate scientific and societal impacts? Toward an analytical and operational framework. Science and Public Policy. https:// doi.org/10.1093/scipol/scy023.

Danneels, E. (2002). The dynamics of product innovation and firm competences. Strategic Management Journal, 23(12), 1095-1121.

Danneels, E. (2008). Organizational antecedents of second-order competences. Strategic Management Journal, 29(5), 519-543.

Diez-Vial, I., \& Montoro-Sanchez, A. (2017). Research evolution in science parks and incubators: foundations and new trends. Scientometrics, 110(3), 1243-1272.

Doblinger, C., Surana, K., \& Anadon, L. D. (2019). Governments as partners: The role of alliances in U.S. cleantech startup innovation. Research Policy, 48(6), 1458-1475.

Feinerer, I., \& Hornik, K. (2012). tm: Text mining package. $R$ package version $0.5-7.1,1(8)$.

Fini, R., Fu, K., Mathisen, M. T., Rasmussen, E., \& Wright, M. (2017). Institutional determinants of university spin-off quantity and quality: a longitudinal, multilevel, cross-country study. Small Business Economics, 48(2), 361-391.

Fini, R., Grimaldi, R., Santoni, S., \& Sobrero, M. (2011). Complements or substitutes? The role of universities and local context in supporting the creation of academic spin-offs. Research Policy, 40(8, SI), 1113-1127.

Fini, R., Rasmussen, E., Siegel, D., \& Wiklund, J. (2018). Rethinking the commercialization of public science: From entrepreneurial outcomes to societal impacts. Academy of Management Perspectives, 32(1), 4-20.

Fisher, G., Kotha, S., \& Lahiri, A. (2016). Changing with the times: An integrated view of identity, legitimacy, and new venture life cycles. Academy of Management Review, 41(3), 383-409.

Franke, N., Gruber, M., Harhoff, D., \& Henkel, J. (2008). Venture capitalists' evaluations of start-up teams: Trade-offs, knock-out criteria, and the impact of VC experience. Entrepreneurship Theory and Practice, 32(3), 459-483.

Galan-Muros, V., van der Sijde, P., Groenewegen, P., \& Baaken, T. (2017). Nurture over nature: How do European universities support their collaboration with business? The Journal of Technology Transfer, 42(1), 184-205.

Gerbin, A., \& Drnovsek, M. (2016). Determinants and public policy implications of academic-industry knowledge transfer in life sciences: A review and a conceptual framework. The Journal of Technology Transfer, 41(5), 979-1076.

Goethner, M., Obschonka, M., Silbereisen, R. K., \& Cantner, U. (2012). Scientists' transition to academic entrepreneurship: Economic and psychological determinants. Journal of Economic Psychology, 33(3), 628-641.

Gonzalez-Pernia, J. L., Kuechle, G., \& Pena-Legazkue, I. (2013). An assessment of the determinants of university technology transfer. Economic Development Quarterly, 27(1), 6-17.

Grimaldi, R., Kenney, M., Siegel, D. S., \& Wright, M. (2011). 30 years after Bayh-Dole: Reassessing academic entrepreneurship. Research Policy, 40(8, SI), 1045-1057.

Guerrero, M., \& Urbano, D. (2012). The development of an entrepreneurial university. The Journal of Technology Transfer, 37(1), 43-74.

Guerrero, M., \& Urbano, D. (2014). Academics' start-up intentions and knowledge filters: An individual perspective of the knowledge spillover theory of entrepreneurship. Small Business Economics, 43(1), 57-74.

Guerrero, M., Urbano, D., Fayolle, A., Klofsten, M., \& Mian, S. (2016). Entrepreneurial universities: emerging models in the new social and economic landscape. Small Business Economics, 47(3, SI), 551-563.

Gümüsay, A. A., \& Bohné, T. M. (2018). Individual and organizational inhibitors to the development of entrepreneurial competencies in universities. Research Policy, 47(2), 363-378.

Harrison, R. T., \& Leitch, C. (2010). Voodoo institution or entrepreneurial university? Spin-off companies, the entrepreneurial system and regional development in the UK. Regional Studies, 44(9), 1241-1262.

Hatak, I., Rauch, A., Fink, M., \& Baranyi, A. (2015). Doing well by being well: The interplay of physical well-being, burn-out symptoms and firm performance of necessity-, rationality- and opportunitydriven entrepreneurs. Frontiers of Entrepreneurship Research, 35(5), 2.

Hayter, C. S. (2016a). Constraining entrepreneurial development: A knowledge-based view of social networks among academic entrepreneurs. Research Policy, 45(2), 475-490. 
Hayter, C. S. (2016b). A trajectory of early-stage spinoff success: the role of knowledge intermediaries within an entrepreneurial university ecosystem. Small Business Economics, 47(3, SI), 633-656.

Hayter, C. S., Nelson, A. J., Zayed, S., \& O'Connor, A. C. (2018). Conceptualizing academic entrepreneurship ecosystems: A review, analysis and extension of the literature. The Journal of Technology Transfer. https://doi.org/10.1007/s10961-018-9657-5.

Hesse, N., \& Sternberg, R. (2017). Alternative growth patterns of university spin-offs: why so many remain small? International Entrepreneurship and Management Journal, 13(3), 953-984.

Hornik, K., Zeileis, A., Hothorn, T., \& Buchta, C. (2007). RWeka: An R interface to Weka. R package version (pp. 3-4).

Huyghe, A., \& Knockaert, M. (2015). The influence of organizational culture and climate on entrepreneurial intentions among research scientists. Journal of Technology Transfer, 40(1), 138-160.

Huyghe, A., Knockaert, M., Piva, E., \& Wright, M. (2016). Are researchers deliberately bypassing the technology transfer office? An analysis of TTO awareness. Small Business Economics, 47(3), 589-607.

Islam, M., Fremeth, A., \& Marcus, A. (2018). Signaling by early stage startups: US government research grants and venture capital funding. Journal of Business Venturing, 33(1), 35-51.

Itri, J. N., Ballard, D. H., Kantartzis, S., Sullivan, J. C., Weisman, J. A., Durand, D. J., et al. (2015). Entrepreneurship in the academic radiology environment. Academic Radiology, 22(1), 14-24.

Jain, S., George, G., \& Maltarich, M. (2009). Academics or entrepreneurs? Investigating role identity modification of university scientists involved in commercialization activity. Research Policy, 38(6), 922-935.

Kessler, M. M. (1963). Bibliographic coupling between scientific papers. American Documentation, 14(1), 10-25.

Kim, P. H., Kotha, R., Fourné, S. P. L., \& Coussement, K. (2019). Taking leaps of faith: Evaluation criteria and resource commitments for early-stage inventions. Research Policy, 48(6), 1429-1444.

Kovács, A., Van Looy, B., \& Cassiman, B. (2015). Exploring the scope of open innovation: A bibliometric review of a decade of research. Scientometrics, 104(3), 951-983.

Lam, A. (2010). From 'Ivory Tower Traditionalists' to 'Entrepreneurial Scientists'? Social Studies of Science, 40(2), 307-340.

Markuerkiaga, L., Caiazza, R., Ignacio Igartua, J., \& Errasti, N. (2016). Factors fostering students' spinoff firm formation: An empirical comparative study of universities from North and South Europe. Journal of Management Development, 35(6), 814-846.

Marzocchi, C., Kitagawa, F., \& Sánchez-Barrioluengo, M. (2017). Evolving missions and university entrepreneurship: academic spin-offs and graduate start-ups in the entrepreneurial society. The Journal of Technology Transfer. https://doi.org/10.1007/s10961-017-9619-3.

Massa, S., \& Testa, S. (2008). Innovation and SMEs: Misaligned perspectives and goals among entrepreneurs, academics, and policy makers. Technovation, 28(7), 393-407.

Mathisen, M. T., \& Rasmussen, E. (2019). The development, growth, and performance of university spin-offs: A critical review. The Journal of Technology Transfer. https://doi.org/10.1007/s1096 1-018-09714-9.

Meusburger, M., \& Antonites, A. J. (2016). Assessing antecedents of entrepreneurial activities of academics at south african universities. International Journal of Innovation Management. https://doi. org/10.1142/S1363919616500584.

Meyer, M., Grant, K., Morlacchi, P., \& Weckowska, D. (2014). Triple Helix indicators as an emergent area of enquiry: A bibliometric perspective. Scientometrics, 99(1), 151-174.

Miranda, F. J., Chamorro, A., \& Rubio, S. (2018). Re-thinking university spin-off: A critical literature review and a research agenda. The Journal of Technology Transfer, 43(4), 1007-1038.

Muscio, A., Quaglione, D., \& Ramaciotti, L. (2016). The effects of university rules on spinoff creation: The case of academia in Italy. Research Policy, 45(7, SI), 1386-1396.

Muscio, A., Quaglione, D., \& Scarpinato, M. (2012). The effects of universities' proximity to industrial districts on university-industry collaboration. China Economic Review, 23(3), 639-650.

O’Kane, C., Mangematin, V., Geoghegan, W., \& Fitzgerald, C. (2015). University technology transfer offices: The search for identity to build legitimacy. Research Policy, 44(2), 421-437.

O'Shea, R. P., Chugh, H., \& Allen, T. J. (2008). Determinants and consequences of university spinoff activity: A conceptual framework. The Journal of Technology Transfer, 33(6), 653-666.

Oosterbeek, H., van Praag, M., \& Ijsselstein, A. (2010). The impact of entrepreneurship education on entrepreneurship skills and motivation. European Economic Review, 54(3), 442-454.

Perkmann, M., Tartari, V., McKelvey, M., Autio, E., Broström, A., D’Este, P., et al. (2013). Academic engagement and commercialisation: A review of the literature on university-industry relations. Research Policy, 42(2), 423-442. 
Philpott, K., Dooley, L., O’Reilly, C., \& Lupton, G. (2011). The entrepreneurial university: Examining the underlying academic tensions. Technovation, 31(4), 161-170.

Prodan, I., \& Drnovsek, M. (2010). Conceptualizing academic-entrepreneurial intentions: An empirical test. Technovation, 30(5-6), 332-347.

Rasmussen, E. (2011). Understanding academic entrepreneurship: Exploring the emergence of university spin-off ventures using process theories. International Small Business Journal, 29(5), 448-471.

Rasmussen, E., \& Borch, O. J. (2010). University capabilities in facilitating entrepreneurship: A longitudinal study of spin-off ventures at mid-range universities. Research Policy, 39(5), 602-612.

Rasmussen, E., Mosey, S., \& Wright, M. (2011). The evolution of entrepreneurial competencies: A longitudinal study of university spin-off venture emergence. Journal of Management Studies, 48(6), 1314-1345.

Rasmussen, E., Mosey, S., \& Wright, M. (2014). The influence of university departments on the evolution of entrepreneurial competencies in spin-off ventures. Research Policy, 43(1), 92-106.

Rasmussen, E., \& Wright, M. (2015). How can universities facilitate academic spin-offs? An entrepreneurial competency perspective. The Journal of Technology Transfer, 40(5), 782-799.

Rothaermel, F. T., Agung, S. D., \& Jiang, L. (2007). University entrepreneurship: A taxonomy of the literature. Industrial and Corporate Change, 16(4), 691-791.

Sandström, C., Wennberg, K., Wallin, M. W., \& Zherlygina, Y. (2018). Public policy for academic entrepreneurship initiatives: A review and critical discussion. The Journal of Technology Transfer, 43(5), 1232-1256.

Secundo, G., Dumay, J., Schiuma, G., \& Passiante, G. (2016). Managing intellectual capital through a collective intelligence approach. Journal of Intellectual Capital, 17(2), 298-319.

Siegel, D. S., \& Wright, M. (2015). Academic entrepreneurship: Time for a rethink? British Journal of Management, 26(4), 582-595.

Skute, I., Zalewska-Kurek, K., Hatak, I., \& de Weerd-Nederhof, P. (2017). Mapping the field: a bibliometric analysis of the literature on university-industry collaborations. The Journal of Technology Transfer. https://doi.org/10.1007/s10961-017-9637-1.

Tartari, V., Perkmann, M., \& Salter, A. (2014). In good company: The influence of peers on industry engagement by academic scientists. Research Policy, 43(7), 1189-1203.

Team, R. C., \& Worldwide, C. (2002). The R stats package. Vienna:R Foundation for Statistical Computing. http://www.R-project.org.

Teixeira, A. A. C., \& Mota, L. (2012). A bibliometric portrait of the evolution, scientific roots and influence of the literature on university-industry links. Scientometrics, 93(3), 719-743.

van Burg, E., Romme, A. G. L., Gilsing, V. A., \& Reymen, I. M. M. J. (2008). Creating university spin-offs: A science-based design perspective. Journal of Product Innovation Management, 25(2), 114-128.

van Eck, N. J., \& Waltman, L. (2007). VOS: A new method for visualizing similarities between objects (pp. 299-306). Berlin: Springer.

van Eck, N. J., \& Waltman, L. (2009). How to normalize cooccurrence data? An analysis of some wellknown similarity measures. Journal of the American Society for Information Science and Technology, 60(8), 1635-1651.

van Eck, N. J., \& Waltman, L. (2010). Software survey: VOSviewer, a computer program for bibliometric mapping. Scientometrics, 84(2), 523-538.

Van Looy, B., Landoni, P., Callaert, J., van Pottelsberghe, B., Sapsalis, E., \& Debackere, K. (2011). Entrepreneurial effectiveness of European universities: An empirical assessment of antecedents and tradeoffs. Research Policy, 40(4), 553-564.

Visintin, F., \& Pittino, D. (2014). Founding team composition and early performance of university-Based spin-off companies. Technovation, 34(1), 31-43.

Vohora, A., Wright, M., \& Lockett, A. (2004). Critical junctures in the development of university high-tech spinout companies. Research Policy, 33(1), 147-175.

Waltman, L., van Eck, N. J., \& Noyons, E. C. M. (2010). A unified approach to mapping and clustering of bibliometric networks. Journal of Informetrics, 4(4), 629-635.

Wright, M. (2014). Academic entrepreneurship, technology transfer and society: Where next? The Journal of Technology Transfer, 39(3), 322-334.

Wright, M., Clarysse, B., Lockett, A., \& Knockaert, M. (2008). Mid-range universities' linkages with industry: Knowledge types and the role of intermediaries. Research Policy, 37(8), 1205-1223.

Zavale, N. C., \& Langa, P. V. (2018). University-industry linkages' literature on Sub-Saharan Africa: Systematic literature review and bibliometric account. Scientometrics, 116(1), 1-49. https://doi. org/10.1007/s11192-018-2760-4. 